\title{
Regulation of B-cell entry into the cell cycle
}

\author{
Sabrina Richards ${ }^{1}$, Chie Watanabe ${ }^{1}$, Lorna Santos ${ }^{1}$, Andrew Craxton ${ }^{1,}{ }^{*}$, and Edward A. \\ Clark $^{1}$ \\ ${ }^{1}$ Department of Immunology and Microbiology, University of Washington, Seattle, WA, USA.
}

\section{Summary}

$\mathrm{B}$ cells are induced to enter the cell cycle by stimuli including ligation of the B-cell receptor (BCR) complex and Toll-like receptor (TLR) agonists. This review discusses the contribution of several molecules, which act at distinct steps in B-cell activation. The adapter molecule Bam32 (Blymphocyte adapter of $32 \mathrm{kDa}$ ) helps promote $\mathrm{BCR}$-induced cell cycle entry, while the secondary messenger superoxide has the opposite effect. Bam32 and superoxide may fine tune BCR-induced activation by competing for the same limited resources, namely Rac1 and the plasma membrane phospholipid $\mathrm{PI}(3,4) \mathrm{P}_{2}$. The co-receptor $\mathrm{CD} 22$ can inhibit $\mathrm{BCR}$-induced proliferation by binding to novel CD22 ligands. Finally, regulators of B-cell survival and death also play roles in B-cell transit through the cell cycle. Caspase 6 negatively regulates CD40- and TLR-dependent $\mathrm{G}_{1}$ entry, while acting later in the cell cycle to promote S-phase entry. Caspase 6 deficiency predisposes B cells to differentiate rather than proliferate after stimulation. Bim, a pro-apoptotic Bcl-2 family member, exerts a positive regulatory effect on cell cycle entry, which is opposed by Bcl-2. New insights into what regulates B-cell transit through the cell cycle may lead to thoughtful design of highly selective drugs that target pathogenic B cells.

\section{Keywords}

cell cycle; CD22; caspase 6; reactive oxygen species; Bam32

\section{Introduction}

B-lymphocyte entry into the cell cycle is a tightly controlled process (1-5). Mitogenic signals derive from a variety of sources: from protein or polysaccharide antigens (Ags) that stimulate the B-cell receptor (BCR), to pathogenic products that signal via Toll-like receptors (TLRs) $(2,5,6)$. Proliferation occurs only at specific points during a B cell's development or during an immune response, when the B cells expand in response to Ags and form germinal centers (GCs) with T-cell help (1-5). Dysregulated proliferation is a hallmark of auto-immunity, where autoreactive $\mathrm{B}$ cells respond to stimulation with activation rather than anergy, and in B-cell cancers, where proliferation can be divorced from external controls (1).

The BCR complex signals B cells through the immuno-receptor tyrosine-based activation motif (ITAM)-containing proteins immunoglobulin $\alpha(\operatorname{Ig} \beta)(C D 79 a)$ and $\operatorname{Ig} \beta(C D 79 b)(2,6)$. BCR ligation initiates the activation of protein tyrosine kinases (PTKs) $(2,6)$ including Lyn, a Src family kinase that phosphorylates the ITAMs, and Syk. Syk phosphorylates the adapter molecule B-cell linker (BLNK)/SLP-65 and promotes activation of signaling pathways

\footnotetext{
(C) 2008 The Authors Journal compilation (C) 2008 Blackwell Munksgaard

Correspondence to: Edward A Clark Department of Immunology and Microbiology University of Washington Box 357650 Seattle, WA 98195, USA Tel.: +206685 2139 Fax: +2066166772 e-mail: eclark@bart.rprc.washington.edu.

*Present address: MRC Toxicology Unit, Hodgkin Building, University of Leicester, Leicester, UK.
} 
depending on Btk and PLC $\gamma 2$ including release of intracellular free calcium $\left[\mathrm{Ca}^{2+}\right]_{\mathrm{i}}$, protein kinase $\mathrm{C}$ (PKC) activation, and mitogen-activated protein kinase (MAPK) family kinase activation $(2,6)$. Signals initiated at the BCR regulate transcriptional, post-transcriptional, and post-translational events, which determine the fate of the B cell: whether it survives, dies, proliferates, or differentiates.

However, signal initiation through the BCR complex does not occur in a vacuum. There are several mechanisms which regulate the quality of signaling after encounter with $\mathrm{Ag}$. The propagation of signaling pathways relies on the close association of elements that do not interact before stimulation. Adapter proteins, while containing no intrinsic enzymatic activity themselves, are crucial in the nucleation of signaling pathways leading to cell fate decisions. Syk phosphorylation of the adapter protein BLNK recruits enzymes such as PLC $\gamma 2$ and additional adapters like Vav that connect the BCR to downstream pathways (7). In BLNK knockout (KO) mice, development past the pre-B-cell stage is severely impaired, and those cells that do progress often fail to fully mature (7). These cells also show deficiencies in $\left[\mathrm{Ca}^{2+}\right]_{\mathrm{i}}$ release, nuclear factor- $\mathrm{\kappa B}(\mathrm{NF}-\mathrm{\kappa B})$ activation, and BCR-induced proliferation (2).

Another level of regulation of BCR signaling is mediated by the association of the BCR complex with co-receptors such as CD22, CD19, CD21, and Fc $\gamma$ RIIB, whose co-ligation with the BCR help modulate signaling (6,8-10). When complement receptor 2 (CR2) (CD21) is associated with CD19, Ag complexed with C3d can co-ligate the BCR and CD19/CD21 and enhance signaling by increased recruitment of phosphoinositide 3-kinase (PI3K). Lipid products of PI3K then recruit Btk to the plasma membrane, enhancing a variety of signaling pathways, including those reliant upon calcium mobilization. Phosphorylation of CD22's immunoreceptor tyrosine-based inhibitory motifs (ITIMs) by Lyn results in recruitment of the Src homology 2 (SH2) domain-containing phosphatase-1 (SHP-1) protein tyrosine phosphatase (PTPase), which can then downmodulate BCR-dependent pathways, possibly by dephosphorylating Syk or PLC 22 (8-10).

Unstimulated B cells are maintained in a state of quiescence, known as $\mathrm{G}_{0}$. Mitogenic signals promote exit from $\mathrm{G}_{0}$ and entry into the cell cycle. During $\mathrm{G}_{1}$, the first phase of the cell cycle, the cell devotes itself to preparing for the DNA replication that will occur in the next phase, S-phase (11). In late $\mathrm{G}_{1}$, the cell passes a restriction point, after which it will enter S-phase and proceed to cell division with minimal input from external stimuli. The mechanisms that control entry into and progression through the cell cycle are varied and complex. Quiescence is in fact an active process and is not maintained merely through a lack of stimulation; thus, mitogenic stimuli must transmit signals that promote not only the upregulation of positive cell cycle regulators but also the deactivation of those factors responsible for repressing the cell cycle. Factors such as the Kruppel-like family of transcription factors, the FOXO subset of forkhead transcription factors, and inhibitors of cyclin-dependent kinases (cdks) all contribute to the active maintenance of quiescence (11-13). Forced expression of these factors in cells motivated to enter the cell cycle often results in arrest in $\mathrm{G}_{1}$, as the cells are unable to pass the restriction point. The restriction point is primarily regulated by retinoblastoma $(\mathrm{Rb})$ family interactions with the E2F transcription factors. In quiescent cells, hypophosphorylated $\mathrm{Rb}$ proteins bind the E2F transcription factors and work to shuttle them out of the nucleus, preventing the initiation of events leading to DNA replication (11). Mitogenic stimulation results in the upregulation of factors termed cyclins, due to the cyclic nature of their expression over the course of the cell cycle (14). In $\mathrm{G}_{1}$, D-type cyclins bind to cdks 4 and 6 , and these activated complexes begin the process of phosphorylating $\mathrm{Rb}$. Late in $\mathrm{G}_{1}$, cyclin $\mathrm{E}$ binds cdk2, and this complex completes the second phosphorylation step of $\mathrm{Rb}$. Hyperphosphorylated $\mathrm{Rb}$ releases the E2F transcription factors, which enter the nucleus and promote the transition to S-phase (14). 
The binding of cyclins to their cdk partners does not in itself guarantee activity; a variety of factors work to inhibit these complexes. One of these is the cyclin-cdk inhibitor p2 $7^{\mathrm{Kip} 1}$. $\mathrm{p} 27^{\mathrm{Kip} 1}$ can inhibit cyclin-cdk complexes, and forced expression of $\mathrm{p} 27^{\mathrm{Kip} 1}$ results in cell cycle arrest before the restriction point (15). To ensure that cyclin-cdk complexes are free to target $\mathrm{Rb} / \mathrm{E} 2 \mathrm{~F}$ complexes, $\mathrm{p} 27^{\mathrm{Kip} 1}$ is targeted for degradation as cells enter the cell cycle, and its levels decrease over the course of $\mathrm{G}_{1}$. Although $\mathrm{p} 27^{\mathrm{Kip} 1}$ is regulated in $\mathrm{G}_{1}$ primarily posttranslationally (11), its transcription is positively regulated by the FOXO family members that contribute to a quiescent state (16). FOXO overexpression also leads to cell cycle arrest, partly through a $27^{\mathrm{Kip} 1}$-dependent mechanism (17).

B lymphocytes enter and progress through the cell cycle utilizing many of the same regulatory components identified in other cell types. The PI3K pathway has been demonstrated to be critical for BCR-induced cell cycle entry (18-20). This pathway regulates the inhibition of the FOXO transcription factors in B cells (18) as well as modulating other pathways, such as the NF- $\kappa B$ pathway, which positively regulates the cell cycle $(19,20)$. These pathways, in turn, upregulate cell cycle-promoting factors such as cyclin D2 and c-myc $(19,20)$. However, the developmental stage of the B cell, B-cell subset, extent of co-receptor ligation, and contribution of other signals modulate the mechanisms that are initiated in a mitogenically stimulated B cell (21). For instance, cyclin D2, while dispensable for B2 B-cell development, is critical for $\mathrm{CD}^{+} \mathrm{B} 1 \mathrm{a}$ B-cell development (22). However, B2 cells rely on cyclin D2 for BCR-induced proliferation (22); extra stimulation through CD40 rescues the proliferative defect in cyclin D2 KO B cells via the upregulation of cyclin D3 (23). Immature B cells stimulated through the BCR complex upregulate cyclin D2 and cdk4 but do not upregulate cyclin E and cdk2, and so fail to transition to S-phase. This defect is overcome by co-treatment with IL-4 (24). While the key role of the PI3K pathway in B-lymphocyte proliferation implicates CD19 co-ligation as an important step for efficient BCR-induced proliferation, other co-receptors can also influence mitogenesis in B cells. CD22 plays a dual role in modulating BCR signals. While it recruits SHP-1 to negatively regulate the BCR, loss of CD22 results in defective BCR-induced proliferation (25). Thus, a variety of signals contribute to whether a stimulated B cell will enter and progress through the cell cycle.

To fully understand how B-cell proliferation is regulated, one must consider not only the role of Ag affinity and upstream adapter proteins, but also the role of B-cell surface co-receptors which can alter BCR and TLR signaling pathways as well as the elements that regulate cell cycle progression in all cells (Fig. 1). Our laboratory studies the signals that regulate B-cell proliferation. This review first discusses recent work in the laboratory elucidating the opposing roles that the adapter protein Bam32 (B-lymphocyte adapter of $32 \mathrm{kDa}$ ) and the NAPDH oxidase (Nox) play in regulating B-cell cycle entry. Then we discuss the role of the co-receptor CD22 in regulating dendritic cell (DC)-dependent B-cell entry into the cell cycle. Finally, we review how the Bcl-2 family members Bcl-2 and Bim and caspases, most notably caspase 6 , modulate B-cell cycle entry and survival. Whether an activated B cell enters the cell cycle and then makes the decision to divide or mature depends on the relative balance (or composite) of a number of factors (Fig. 1).

\section{Regulation of B-cell entry into the cell cycle by the adapter Bam32 and the NADPH oxidase}

After BCR triggering, the PTKs Syk and Lyn initiate signaling cascades by phosphorylating target proteins (6). The balance between phosphorylation and dephosphorylation is important for modulating signaling cascades, ensuring proper attenuation of signaling (6). B-cellassociated adapter proteins play a key function to integrate signaling and bring together active enzymes with their respective targets $(6,26)$. 
Our laboratory has focused on characterizing Bam32, also known as DAPP1 $(27,28)$. We found that Bam32 is expressed at high levels in GC B cells and is regulated downstream of PI3K (28). Bam32 contains a C-terminal pleckstrin homology ( $\mathrm{PH}$ ) domain as well as an $\mathrm{SH} 2$ domain in its N-terminus. After BCR ligation, Bam32 is quickly phosphorylated on tyrosine 139 (Y139) in a Src kinase-dependent manner (28) and translocates to the plasma membrane via its PH domain (Fig. 2). Bam32's recruitment to the plasma membrane relies not only on an intact phosphoinositide-binding motif in the PH domain but also on the activity of PI3K (27). Additionally, Bam32 in chicken DT40 and human BJAB B-cell lines regulates $\left[\mathrm{Ca}^{2+}\right]_{\mathrm{i}}$ via an association with phospholipase C $\gamma 2$ (PLC $\gamma 2)(29,30)$. Further studies using B-cell lines revealed Bam32's role in a variety of processes. Most striking was the finding that Bam32 regulates the actin network in B cells via the Rac1 guanosine triphosphatase (GTPase) (31, 32). Rac1, a Rho-family GTPase, has been shown to regulate actin polymerization and membrane ruffling, and these studies linked Bam32 to Rac regulation $(30,31,33)$. In cells overexpressing Bam32, Rac1 activity as well as basal levels of F-actin increased. To regulate actin-associated cytoskeleton, Bam32 must be phosphorylated on Y139, most likely by Lyn, and must have intact $\mathrm{PH}$ and $\mathrm{SH} 2$ domains (Fig. 2), indicating that this process relies on Bam32's binding to target inositides and its role as an adapter (31). In conjunction with its role linking the BCR to actin polymerization, Bam32 also enhances signaling pathways leading to MAPK pathways and cell survival (30).

One of the most striking aspects about Bam32 is the unusual propensity of its $\mathrm{PH}$ domain to bind $\mathrm{PI}(3,4) \mathrm{P}_{2}$ more strongly than $\mathrm{PI}(3,4,5) \mathrm{P}_{3}(28,34)$ (Fig. 2). After BCR ligation, PI3K catalyzes the formation of $\mathrm{PIP}_{3}$ from $\mathrm{PI}(4,5) \mathrm{P}_{2}$. The $\mathrm{SH} 2$-containing inositol polyphosphate 5-phosphatase (SHIP) then converts $\mathrm{PI}(3,4,5) \mathrm{P}_{3}$ to $\mathrm{PI}(3,4) \mathrm{P}_{2}(35)$. Thus, while plasma membrane recruitment of Bam32 is dependent on PI3K activity, Bam32 is different from other PI3K-dependent proteins such as Btk, as its recruitment occurs under circumstances where most PI3K-dependent pathways are attenuated (34).

The data demonstrating the crucial role of Bam32 in proximal BCR signaling persuaded two groups to investigate Bam32 in primary B cells by creating Bam32 KO mice $(36,37)$. While Han et al. (36) detected a defect in B-cell development, a reduction in the percent of peritoneal $\mathrm{CD}^{+} \mathrm{B} 1 \mathrm{a}$ cells, Fournier et al. (37) did not. However, both groups found that Bam32 KO B cells have a dramatic reduction in BCR-induced proliferation but little perturbation in response to other mitogens $(36,37)$. In conjunction with a defective response to BCR-induced proliferation, T-independent type 2 (TI-2) responses in vivo were severely decreased, including a severe reduction in the level of $\mathrm{Ag}$-specific serum $\mathrm{IgG}_{3}$, a hallmark TI-2 isotype (36,37). Additionally, Bam32 KO B cells did not have any obvious defects in survival in vitro, suggesting that Bam32 participated in a BCR pathway regulating proliferation but not survival (36). In neither case was the biochemical basis for the hypoproliferative defect demonstrated.

Further studies discussed by Marshall et al. (38) link in vivo data to the specificity of Bam32's $\mathrm{PH}$ domain for $\mathrm{PI}(3,4) \mathrm{P}_{2}(34)$. Bam32's translocation to the membrane is dependent upon PI3K activity, but Bam32 translocates under situations where most PI3K-dependent pathways are attenuated, namely after SHIP hydrolyzes the PI3K product $\mathrm{PI}(3,4,5) \mathrm{P}_{3}$ to $\mathrm{PI}(3,4) \mathrm{P}_{2}$ (34). Bam32's later recruitment suggested the model that Bam32 may function to help maintain or sustain certain signaling pathways. Marshall's group (38) studied the T-dependent antibody responses in Bam32 KO mice more closely; they demonstrated that while total IgG appeared normal, maintenance of GCs and affinity maturation were reduced in KO mice. This correlated with isotype-specific deficiencies in class-switching. These data led to the hypothesis that Bam32 works to sustain BCR-induced responses.

Our laboratory has investigated the cell cycle defect in Bam32 KO B cells. We were interested in defining at which point in the cell cycle Bam32 exerts its regulatory activity, given that a 
lack of proliferation did not distinguish between cells unable to exit quiescence, cells arrested in $\mathrm{G}_{1}$, or cells arrested at some later point in the cell cycle and unable to proceed through division. We first looked at the cell cycle status of BCR-triggered Bam32 two ways. After mitogenic stimulation, blasting lymphocytes increase their size and RNA as they progress through $\mathrm{G}_{1}$-phase and prepare for $\mathrm{S}$-phase. We used forward scatter to measure cell size, and the RNA stain Pyronin- $Y(P-Y)$ to distinguish between $G_{0}$ and $G_{1}$ cell cycle stages (39). After stimulating wildtype (WT) and Bam32 KO B cells with graded doses of anti-IgM, we found that Bam32 KO B cells displayed defective increases in size and RNA content (40). This finding suggested that Bam32 KO B cells were defective either in exit from quiescence or progression to later stages of $\mathrm{G}_{1}$. Because the data did not distinguish between these two possibilities, we investigated the cell cycle defect in Bam32 KO B cells further.

We compared activated WT and Bam32 KO B cells for several hallmarks of $\mathrm{G}_{1}$ progression: sequential $\mathrm{Rb}$ phosphorylation and the upregulation of cyclins. As mentioned previously, the $\mathrm{Rb}$ protein is phosphorylated in two stages: firstly by D-type cyclins complexed with cdk4/6 and secondly by cyclin E complexed with cdk2 (14). It is this second phosphorylation event that marks the restriction point, the bottleneck to entering S-phase $(11,14)$. When we probed $\mathrm{Rb}$ phosphorylation events in BCR-stimulated WT and Bam32 KO B cells, we detected delayed phosphorylation at the cyclin D-dependent site. Phosphorylation at the second, cyclin Edependent site was almost undetectable (40). Additionally, while cyclin D2 protein levels were upregulated normally, cyclin D3 was not upregulated in BCR-stimulated Bam32 KO B cells. C-myc, a positive regulator of the cell cycle, and cdk4, which cooperates with D-type cyclins in $\mathrm{G}_{1}$, were poorly upregulated in BCR-stimulated Bam32KO B cells compared with WT (40). In conjunction with noticeable defects in cyclin E-dependent phosphorylation, we demonstrated that $\mathrm{p} 27^{\mathrm{Kip} 1}$, an inhibitor of cyclin E, was not downregulated efficiently in Bam32 KO B cells. These data indicate dysregulation in events controlling the late- $\mathrm{G}_{1}$ restriction point. Although Bam32 KO B cells may be able to enter into early $\mathrm{G}_{1}$-phase, they exhibit inefficient progression to later $\mathrm{G}_{1}$ stages that promote $S$-phase entry.

Because it was unclear which pathway leading from the BCR to cell cycle entry is defective in Bam32 KO mice and it had been proposed that Bam32 may play a role in sustaining PI3Kdependent signaling pathways (38), we tested the idea that Bam32 may play a role in maintaining signals initiated through the BCR complex. We compared BCR-induced proliferation between WT B cells, Bam32 KO B cells, and WT B cells where the stimulating antibody was washed away after $24 \mathrm{~h}$. Bam32 KO B cells proliferated as poorly or even more poorly than the WT B cells whose stimulus was prematurely removed. Considered with the data described by Marshall et al. (38), these data support the possibility that Bam32 may act to sustain a signaling pathway, the outcome through which relies on signal maintenance (34).

We also studied the role of Bam32 in regulating more proximal BCR-induced signaling pathways. Using WT and Bam32-deficient DT40 B-cell lines and DT40 cells overexpressing Bam32, we tested if Bam32 might play a role in BCR-induced superoxide generation.

Surprisingly, cells lacking Bam 32 generated increased levels of superoxide after BCR ligation compared with WT cells (40). Similarly, Bam32 KO splenic B cells also had elevated BCRinduced superoxide production. Conversely, in cells overexpressing Bam32, BCR-induced superoxide was barely detectable (40). The generation of superoxide after BCR ligation in Bam32 KO B cells was inversely correlated with the effect of Bam32 on Rac activity and actin polymerization (31) (Table 1). Thus, Bam32 may play both positive and negative roles in regulating pathways downstream of the BCR.

These surprising data intrigued us, particularly because a growing body of evidence has implicated superoxide and its derivatives, known as reactive oxygen species (ROS), in the modulation of signaling pathways in non-phagocytic cells. Non-phagocytic cells, rather than 
producing large amounts of superoxide targeted at killing pathogens, are able to produce small, localized amounts of superoxide after stimulation through a variety of receptors (41-45, M. Reth, this volume). In these cells, ROS act on the balance between tyrosine phosphorylation and dephosphorylation. Rather than acting to enhance the activity of PTKs, superoxides instead act to inhibit dephosphorylation, shifting the balance toward phosphorylation and helping to modulate the intensity of receptor signaling (41-45). ROS target the cysteines in the active site of PTPases. Reversible phosphorylation of these cysteines renders the PTPase temporarily inactive, allowing the PTK to work unimpeded (44). Superoxide can be produced from a variety of sources, including the mitochondria (42), and an inducible, membrane-bound complex known as Nox (46).

Nox is a multi-component enzyme present not only in phagocytic cells but also in a variety of non-phagocytic cell types (46). In a resting cell, Nox is inactive and comprised of two component groups: the membrane-bound catalytic component flavocytochrome b558 (gp91 phox and $\mathrm{p} 22^{\text {phox }}$ ), and the cytosolic complex of $\mathrm{p} 47^{\text {phox }}$, $\mathrm{p} 67^{\text {phox }}$, and $\mathrm{p} 40^{\text {phox }}$. After activation, PKC phosphorylates the cytosolic components, leading to conformational changes that allow them to translocate to the surface and complex with gp91 phox and $\mathrm{p} 22^{\text {phox }}$. Integral to this translocation step is the phox (PX) domain of $\mathrm{p} 47^{\text {phox }}$, which binds to $\mathrm{PI}(3,4) \mathrm{P}_{2}$ in the plasma membrane (47). Also required for generation of the oxygen radical by this enzyme is activated Rac GTPase (46) (Fig. 2). B lymphocytes express these same components utilized in phagocytic cells for inducible superoxide generation. Compared with the levels of superoxide produced by phagocytes, B cells generate only 5-10\% as much, which may be levels explained by the much reduced expression in B cells of gp91 ${ }^{\text {phox }}$, the catalytic component of the oxidase (48).

Among the receptors identified as capable of stimulating superoxide generation is the BCR complex (48). A few studies have also implicated ROS in the regulation of BCR-initiated signaling pathways $(45,49,50)$. It has long been known that treatment of $B$ cells with hydrogen peroxide generates strong tyrosine phosphorylation in mimicry of BCR stimulation, at least in part $(45,49)$. But these studies left open the question of whether superoxides generated in lower levels by BCR triggering actually play a significant role in modulating signaling pathways. A recent study examined superoxide derivatives and BCR signaling in A20 cells (50). Utilizing pharmacological inhibitors, Singh et al. (50) identified a positive feedback loop between calcium signaling and superoxide signaling. Additionally, this study implicated Lyn as a PTK whose activity was targeted by an unknown superoxide-regulated PTPase (50). These data suggested a model whereby Lyn activity is increased in the presence of BCR-induced superoxide through a Lyn-inhibiting PTPase being itself inhibited by ROS. In other words, superoxides may enhance signaling pathways through the BCR by indirectly targeting a proximal PTK (51).

A limitation of the research on the role of ROS in B-cell signaling is that it is based on data from cell lines. Given that the regulation of key signaling pathways can be different or altered in continuously dividing cell lines and primary lymphocytes, we decided to further investigate the role of Nox in B cells using a mouse model. We obtained mice deficient in the gp91phox catalytic component of Nox (52). These mice are a model for chronic granulomatous disease and produce no detectable superoxide after BCR stimulation $(51,53)$. As with Bam32 KO mice (32-34), we detected no defects in B-cell development in gp91 ${ }^{\text {phox }} \mathrm{KO}$ mice (53). Our results using gp91 ${ }^{\text {phox }}$ KO B cells differ from that produced by Singh et al. (50) using A20 cells. Based on their data, Singh et al. proposed that superoxide downstream of the BCR acts to modulate the amplitude of $\left[\mathrm{Ca}^{2+}\right]_{\mathrm{i}}$ mobilization; however, we detected no differences in BCR-induced $\left[\mathrm{Ca}^{2+}\right]_{\mathrm{i}}$ between WT and gp91 ${ }^{\text {phox }} \mathrm{KO}$ B cells (53). These results in conjunction with other data generated in DT40 cell lines (40) have led us to conclude that BCR-induced $\left[\mathrm{Ca}^{2+}\right]_{\mathrm{i}}$ is upstream of superoxide generation (53, authors' unpublished data). 
Given the hypoproliferative phenotype of the Bam32 KO B cells as well as the increase in superoxide production in the Bam $32 \mathrm{KO}$ cells, we decided to assess BCR-induced proliferation in gp91 phox $\mathrm{KO}$ B cells. In direct contrast to Bam32 KO B cells, B cells deficient in gp91 ${ }^{\text {phox }}$ responded to BCR stimulation with enhanced proliferation (53). More gp9 ${ }^{\text {phox }} \mathrm{KO}$ $\mathrm{B}$ cells than WT B cells increased their RNA content after BCR stimulation, indicating a higher propensity to exit $\mathrm{G}_{0}$ and enter the cell cycle (53). But why would more cells enter the cell cycle? We measured protein levels of various cell cycle regulators, including cyclin D2 and p27 Kip1 $(11,14)$. While BCR-induced cyclin D2 upregulation appeared unperturbed in gp91 $1^{\text {phox }} \mathrm{KO} \mathrm{B}$ cells, the downregulation of $\mathrm{p} 27^{\mathrm{Kip} 1}$ protein levels was accelerated (53). Thus, it appears that the enhanced $\mathrm{G}_{1}$ entry or progression in gp9 ${ }^{\text {phox }} \mathrm{KO} \mathrm{B}$ cells is due to faster induction of cyclin-cdk activity, as the inhibitory factors are downregulated more quickly.

To extend these studies to in vivo regulation of B-cell proliferation, we immunized WT and gp91 ${ }^{\text {phox }} \mathrm{KO}$ mice with a TI-2 Ag, dinitrophenol (DNP)-Ficoll, and monitored the development of anti-DNP antibodies. We reasoned that this in vivo response would be most likely to rely on B-cell-intrinsic factors, with less confounding contributions from $\mathrm{T}$ cells, and also that it would be valuable to compare gp9 ${ }^{\text {phox }} \mathrm{KO}$ mouse responses with the known TI-2 defect in Bam32 KO mice (36,37). Surprisingly, gp91 ${ }^{p h o x} \mathrm{KO}$ mice generated a strongly enhanced antiDNP antibody response. Ag-specific IgM levels in gp91 ${ }^{\text {phox }} \mathrm{KO}$ mice were significantly increased compared with levels in WT mice. Furthermore, we also found that Ag-specific serum $\mathrm{IgG}_{1}$ was also elevated in gp91 ${ }^{\text {phox }} \mathrm{KO}$ mice after immunization, suggesting a possible dysregulation in the response of gp91 ${ }^{\text {phox }} \mathrm{KO}$ B cells to IL-4 (53)

While studies in cell lines have pointed to superoxides as factors that enhance phosphotyrosine-dependent signaling pathways, the story may be more complex. Loss of superoxide signaling in primary cells leads to a hyper-responsive phenotype to BCR stimulation, indicating that superoxides target an inhibitory pathway rather than just an excitatory pathway (53). Although our data differ in some aspects with those of Singh et al. (50), we agree with the model that the PTK Lyn is a likely target for the superoxide pathway. In this model, the presence of superoxide in WT B cells results in the inhibition of a PTPase that targets Lyn, leading in turn to enhanced Lyn activity. Loss of superoxide would lead instead to enhanced PTP activity and reduced Lyn activity. Consistent with our findings and this model, B cells from mice expressing constitutively active Lyn respond to BCR triggering with reduced proliferation (54), while those lacking Lyn respond with enhanced proliferation (55). We propose that loss of superoxide will result in enhanced proliferation in the presence of enhanced PTPase activity.

Bam32 and BCR-induced superoxide appear to differentially modulate signaling pathways leading to BCR-induced cell cycle entry and proliferation $(36,37,40,53)$. However, several aspects of the data indicate to us that there is a balanced interplay between these regulators of BCR signaling (Fig. 2). First, both Bam32 and p4 $7^{\text {phox }}$ contain domains specific for PI $(3,4)$ $\mathrm{P}_{2}$, unusual among proteins specific for phosphoinositides, and these domains are crucial for their membrane targeting and roles in modulating signaling pathways $(27,34,47)$. Second, both Nox and Bam32 rely on GTP-bound Rac to mediate their regulatory functions $(31,46)$. We propose that the Bam 32 and Nox compete for a limited pool of resources, and this competition explains in part the opposite phenotypes we detected in Bam 32 and gp91 ${ }^{\text {phox }}$ KO B cells (Fig. 2). Bam32 may regulate the level of superoxide generated by reducing the amount of phosphoinositide accessible to $47^{p h o x}$, as well as the availability of active Rac to stimulate the Nox. When Bam32 is missing, more Nox complexes are able to form at the membrane, and more of these are activated due to the inclusion of a greater supply of Rac1. This increase in superoxide may contribute indirectly to the Bam32 KO B-cell phenotype, where more superoxide is available to stimulate a pathway inhibitory to cell cycle entry. 


\section{Regulation of DC-dependent B-cell proliferation by CD22}

The regulation of T-cell responses by DCs has been extensively studied (56-58); it is less well appreciated that DCs can also directly influence B-cell responses. For instance, DCs produce soluble factors including IL-12, IL-6, B-cell activating factor of the tumor necrosis factor family (BAFF), also know as B-lymphocyte stimulator (BLyS), and type I interferons, which have a range of different effects on $B$ cells including regulation of proliferation, differentiation, antibody secretion, and isotype class switching (59-64). In addition to secreting soluble factors, DCs can also exert their effects on B cells by direct cell-to-cell interactions. The interaction between CD40 on B cells with CD40L on DCs results in production and secretion of IgG and IgA $(65,66)$. Furthermore, DCs have the ability to retain native Ag that is re-expressed on the cell surface on certain Fc receptors (Fc $\gamma$ RIIB) via a non-degrading recycling pathway. This native $\mathrm{Ag}$ can be presented to $\mathrm{B}$ cells, suggesting that the interaction of B cells with DCs may be important for antibody production (67). B cells also interact with DCs that retain specific $\mathrm{Ag}$ after exiting the high endothelial venules but before entry into the follicles of lymph nodes (68). This interaction, which requires direct cell-to-cell contact, results in B-cell activation and Ag transfer from the DCs to the Ag-specific B cells.

Our laboratory previously showed that human monocyte-derived DCs can promote B-cell proliferation through a process dependent on BAFF (62). In assessing whether the same was true of mouse DCs, we found that while mature bone marrow (BM)-derived DCs ( $\mathrm{mDCs}$ ) promoted B-cell proliferation, immature BM-derived DCs (iDCs) and purified CD11 $\mathrm{c}^{+}$splenic DCs inhibited BCR-induced proliferation of B cells (69). This decreased proliferation induced by iDCs was not due to increased cell death, because B-cell viability was higher when iDCs and B cells were in contact with one another. Additionally, this iDC-dependent inhibition of $\mathrm{B}$-cell division could be overridden by adding graded doses of BAFF to the cultures. These data are consistent with the model that DCs are unable to induce B-cell proliferation unless the $\mathrm{B}$ cell receives two signals, one through the BCR and a second signal from the DCs (60). We also observed that this inhibition of B-cell proliferation also requires direct contact between the B cells and iDCs, because there was no inhibition observed when the two cell types were physically separated using transwells. This inhibition of B cells by iDCs but not mDCs is reminiscent of the ability of DCs to regulate T-cell responses $(70,71)$ : mDCs stimulate while iDCs inhibit $\mathrm{T}$ cells by inducing anergy.

How then is contact-dependent inhibition of B cells mediated by certain types of DCs? We suspected that an inhibitory receptor expressed on B cells was involved, because physical interaction between DCs and B cells was required for DC-mediated inhibition. We discovered that the inhibitory receptor was the B-cell-restricted surface molecule CD22. CD22 was an attractive candidate, because it is an adhesion molecule with ligands (CD22L) expressed on hematopoietic cells. In addition, the cytoplasmic domain of CD22 contains three tyrosine residues that exist within ITIMs. Finally, CD22 can physically interact with the BCR complex and inhibit BCR signaling through recruitment of the SHP-1 PTPase via the ITIMs (72-74). Unlike WT B cells, CD22 KO B cells continued to proliferate equally well in the presence or absence of iDCs and at the different $\mathrm{B}$ cell:DC ratios we examined.

The known ligands for CD22 contain $\alpha 2-6$ sialic acid linkages generated by the ST6Gal-I sialyltransferase; thus, we decided to test if iDCs obtained from ST6Gal-I sialyltransferase (ST6Gal-I) KO mice (75) fail to inhibit B-cell proliferation. Surprisingly, ST6Gal-I KO iDCs, even though they do not express $\alpha 2-6$ sialic acid-containing ligands for CD22, inhibited Bcell proliferation (69). Thus, DC-mediated inhibition of B cells requires CD22 but not a2-6 sialic acid-containing CD22L. Using a soluble CD22 fusion protein (76), we found that iDCs and splenic and BM CD11 $\mathrm{c}^{+}$DC subsets from either WT or ST6Gal-I KO mice express a second CD22L, or set of CD22Ls (DC-CD22L), that is not dependent on $\alpha 2-6$ sialic acid 
linkages. The CD22L that is comprised mostly of $\alpha 2-6$ sialic acid-containing glycans generated by ST6Gal-I is expressed at high levels on WT B cells but not on ST6Gal-I KO B cells, and thus we refer to it as B-CD22L. Thus, B cells and DCs clearly express distinct sets of CD22 ligands.

Little is known about the identity of the CD22Ls. What is known is that CD22 can bind to its ligands both in cis (on the same cell surface) and in trans (on a different cell surface) (77-79). The distinct CD22Ls on B cells and non-B cells are likely to have different functions. CD22 binding to ST6Gal-I-dependent B-cell CD22L in cis may have a function distinct from CD22 binding to ST6Gal-I-independent DC-CD22L in trans (Fig. 3). The binding of CD22L in cis on B cells is very likely to be important for the regulation of BCR signaling thresholds (77, 80-82). In resting B cells, CD22 binds to CD22Ls, including the BCR and CD22 itself. Although the majority of CD22 is present in homomultimeric complexes, some CD22 molecules form heterotypic interactions with the BCR $(74,83)$ (Fig. 3A). Both of these homotypic and heterotypic cis interactions require $\alpha 2-6$ sialic acid modifications. This binding to B-CD22L in cis is likely to attenuate BCR signaling. Therefore, in the absence of ST6gal$\mathrm{I}$, one would expect the BCR signal strength to increase. Some groups have reported that the BCR and CD22 colocalize more in the absence of ST6Gal-I $(78,84)$. Although the microscopy data are compelling, these reports did not show direct interaction between the BCR and CD22. It is possible that even though the BCR and CD22 can co-localize to the same area within clathrin-rich domains of the plasma membrane of $\mathrm{B}$ cells, they may be unable to interact normally due to a lack of $\alpha 2-6$ sialic acid modifications. This lack of interaction could lead to a stronger BCR signal.

What would be the expected effect of cis CD22-CD22L-mediated attenuation on BCR signaling? A number of studies suggest that weaker BCR signaling favors the development of marginal zone (MZ) B cells and stronger signaling favors the development of follicular (FO) $\mathrm{B}$ cells $(2,85)$. For instance, Cariappa and colleagues $(78)$ found that Aiolos KO mice with enhanced BCR signaling have more FO B cells and fewer MZ B cells. Casola et al. (86) showed that reducing the strength of $\mathrm{BCR}$ signaling favors $\mathrm{MZB}$-cell maturation. These findings would suggest that CD22 and ST6Gal-I KO mice, which lack attenuation of BCR signaling via the cis $\mathrm{B}-\mathrm{CD} 22 \mathrm{~L}$, would have reduced numbers of $\mathrm{MZ} \mathrm{B}$ cells, and indeed both $\mathrm{MZ}$ precursors and MZ B cells are reduced in CD22 and ST6Gal-I KO mice (Fig. 3A).

What might be the in vivo role of trans CD22-CD22L interactions occurring between B cells and DCs? A significant clue comes from comparing the phenotype of CD22 KO mice, which are missing both cis and trans activities, compared with ST6Gal-I KO mice, which have no cis CD22-CD22L interactions but have intact trans CD22-CD22L signaling (69). When we and others examined the number of long-lived BM B cells $\left(\mathrm{B} 220^{+} \operatorname{IgM}^{+} \mathrm{CD} 24^{10}\right)(87,88)$ in the CD22 and ST6Gal-I KO mice, ST6Gal-I KO mice were found to have normal numbers of longlived BM B cells compared with WT mice $(69,75,84)$. CD22 KO mice, however, had fewer mature BM B cells compared with WT mice (25). The fact that the CD22L on DCs can still interact with CD22 in trans in the ST6Gal-I KO mice might explain why these mice have normal numbers of BM B cells, even in the absence of cis interactions (Fig. 3B). According to this model, CD22 can bind to its trans ligands on DCs, leading to disruption of the homomultimeric CD22 complexes. Indeed, it was previously reported that on some cells, CD22 binding to trans ligands may be favored over binding to cis ligands (89). Once dispersed, more individual CD22 molecules could then interact with BCR complexes via cis interactions, resulting in the inhibition of B-cell proliferation (Fig. 3B; 1). Alternatively, binding of CD22 in trans to DC-CD22L (Fig. 3B;2) might also result in BCR signal inhibition. Direct ligation of CD22 can induce BCR-independent tyrosine phosphorylation of CD22, the recruitment of SHP-1, and an inhibitory signaling cascade $(25,72,90,91)$. This activity could prevent proliferation while at the same time maintaining quiescence and thus survival (Fig. 3B). 
Although the cis interactions between the BCR and CD22 provide a low level of inhibitory signaling (Fig. 3A), the CD22 trans interactions with the DC-CD22L increase the inhibitory signals to the B cells via both BCR-dependent and -independent mechanisms. Therefore, we would propose that in the absence of CD22, the numbers of mature long-lived BM B cells are reduced, because $\mathrm{CD} 22$ is not present and hence interactions between $\mathrm{B}$ cells and DCs via the trans $\mathrm{CD} 22 \mathrm{~L}$ cannot occur. This model also would explain why B cells turnover faster in CD22 KO mice (25). Lanoue et al. (92) reported that Ag-bearing cells expressing CD22L attenuated B-cell activation. They suggested that trans CD22-CD22L interactions may be important for attenuating B-cell responses to self-Ag. The model in Fig. 3B is consistent with this suggestion, while underscoring the importance of CD22Ls that are not dependent on modifications generated by ST6Gal-I.

We propose that BCR signaling threshold is controlled mainly by CD22 cis interactions, while B-cell survival is regulated by CD22 trans interactions with DC-CD22L, which affects the maintenance of long-lived B cells in the BM (Fig. 3). This model may be over-simplistic; for instance, it is likely that there is some interplay and competition between cis CD22L and trans CD22L. Finally, testing the validity of this model with require the characterization of the DC-CD22L and understanding more about how both B cell and CD-CD22L expression and interactions with CD22 are regulated. Some evidence suggests that the CD22L may play an important role in the maintenance of tolerance to self-Ag (92). Discovering the identity of the second CD22L could certainly be of great therapeutic value and could possibly be used in the treatment of autoimmune diseases involving B cells.

\section{Regulation of B-cell entry into the cell cycle by $\mathrm{Bcl}-2$ family members}

The 'Bcl-2 homology 3 (BH3)-only' subgroup of the Bcl-2 family (Bid, Bad, Bik, Bim, Bmf, Hrk/DP5, Noxa, and Puma) shares the BH3 domain with other Bcl-2 family members and is pro-apoptotic (93-95). BH3-only proteins serve as sentinels for specific apoptotic stimuli and initiate apoptosis via interaction and blockade of pro-survival Bcl-2 family members (94) or alternatively some BH3-only proteins such as Bim may directly activate Bax and/or Bak (96). The BH3-only protein Bim, in particular, regulates apoptosis of hematopoietic cells including B and T cells, macrophages, and granulocytes (97). Bim is required for negative selection of T cells and is upregulated after T-cell receptor (TCR) ligation (98). Similarly, BCR-induced death is decreased in Bim KO B cells, and the deletion of autoreactive B cells is inhibited in Bim KO mice $(99,100)$. Anergic B cells from tolerant anti-Ig/HEL-double transgenic (Tg) mice express elevated levels of Bim mRNA and protein (101), suggesting that Bim may help regulate B-cell anergy or selection. Bim expression in B cells is regulated by the B-cell survival and maturation factor BAFF, which down-regulates Bim protein levels and blocks association of Bim with Bcl-2 (100).

Surprisingly, Bim KO and Bcl-2 Tg mice have very similar alterations in their splenic B-cell populations: both have elevated numbers of T2 and FO B cells, yet unexpectedly, both have decreased numbers of MZ B cells (100,102-104). Interestingly, defects present in Bcl-2 KO mice - polycystic kidney disease, runting, graying, and lymphoid organ degeneration - are restored in Bcl-2/Bim double $\mathrm{KO}$ mice $(105,106)$. These results suggest that $\mathrm{Bcl}-2$ and Bim are major functional antagonists in some cell types, including hematopoietic cells.

The fact that the regulation of lymphocyte cell survival is coupled to control of cell growth is clearly illustrated by the fact that Bcl-2 family members not only control cell fate but also control entry into the cell cycle. Hence, B and T cells overexpressing Bcl-2 have delayed cell cycle entry and increased survival $(107,108)$, while Bcl-2-deficient T cells more rapidly enter cell cycle and die (109). The slower cell cycle entry induced by Bcl-2 is associated with both 
increased expression and delayed degradation of $\mathrm{p}^{\mathrm{Kip} 1}$ (described earlier in review) and of the $\mathrm{Rb}$ family member $\mathrm{p} 130$, and not with changes in cdk inhibitor $\mathrm{p} 21^{\mathrm{Cip} 1}(110,111)$.

Because Bim may be an antagonist of Bcl-2, we tested whether Bim deficiency affects entry of B cells into the cell cycle (112). Compared with WT B cells, Bim KO B cells had reduced proliferation in response to BCR, TLR3, or TLR4 signaling but not to TLR9 signaling. Reduced cell division correlated with a delay in the transition from $\mathrm{G}_{0}$ to $\mathrm{G}_{1}$ and a reduction of p130 and $\mathrm{p} 27^{\mathrm{kip} 1}$ degradation. These results are consistent with the antiproliferative defects observed in Bcl-2 Tg B cells $(107,108)$.

To our surprise, Bim KO B cells also displayed a proximal defect in BCR signaling: BCRinduced increases in cytosolic calcium levels were significantly delayed in Bim KO compared with WT B cells due to reduced calcium mobilization from intracellular stores (112). The finding that Bim affects $\left[\mathrm{Ca}^{2+}\right]_{\mathrm{i}}$ release suggests that it may act at the level of the endoplasmic reticulum (ER). Bim can associate with ER membranes (113), so it could affect $\left[\mathrm{Ca}^{2+}\right]_{\mathrm{i}}$ at the ER by directly interacting with $\mathrm{Bcl}-2$. Because $\mathrm{Bcl}-2$ can dampen TCR-induced calcium release through its interaction with IP3R (114), Bim may promote BCR-induced calcium release by binding either directly to Bcl-2 or by competing with Bcl-2 so that it does not bind to IP3R. This mechanism could have feedback controls, because Bim expression is regulated by calcium $(115,116)$.

These data suggest that Bim may regulate B-cell entry into the cell cycle at a point triggered very early after BCR activation, which leads to enhanced degradation of $\mathrm{p} 27^{\mathrm{kip} 1}$ and increased proliferation (Fig. 1). Thus, Bim and Bam32 appear to have related functions, in that they both regulate early events in B cells that promote cell cycle entry. However, to what extent the effect of Bim on $\left[\mathrm{Ca}^{2+}\right]_{\mathrm{i}}$ contributes to cell cycle entry remains unclear. Because Bim regulates cell cycle entry of B cells stimulated with either lipopolysaccharide (LPS) or polyinosinicpolycytidylic acid, which do not induce a strong release of $\left[\mathrm{Ca}^{2+}\right]_{i}$, itseemsunlikely that Bim affects B-cell cycle entry solely via regulation of $\left[\mathrm{Ca}^{2+}\right]_{\mathrm{i}}$.

Interestingly, Bcl-2 $\mathrm{Tg}$ mice have moderately delayed but dramatically prolonged $\operatorname{IgM}$ and IgG antibody responses to sheep erythrocytes (116), consistent with an initial reduction in proliferative rate followed by greatly enhanced B-cell survival. Further studies are required to establish whether Bim $\mathrm{KO}$ mice also exhibit similar defective immune responses to T-D and/ or T-I 2 Ag. Overall, our results suggest that the balance of pro- and anti-apoptotic Bcl-2 family proteins is critical for controlling both cell cycle progression and apoptosis in B cells.

\section{Caspases regulate B-cell activation, proliferation, and differentiation}

Caspases are a family of well-known aspartic acid-specific proteases, which regulate apoptosis in multiple organisms ranging from invertebrates to mammals. Fourteen mammalian caspases have been identified that can be divided into three groups based on their structure and function: cytokine activators caspases (caspase-1, $-4,-5,-11$, and -12); apoptotic initiator caspases (caspase-2, -8, -9, and -10); and effector caspases (caspase-3, -6, and -7) (117). Although caspase-independent programmed cell death has been described, caspase-dependent apoptosis pathways are well characterized and also conserved in metazoan evolution (118-120).

Generally, after apoptotic stimulation, initiator caspases are activated, which in turn cleave and activate effector caspases (121). Activated effector caspases target many cellular molecules as their specific substrates; over 400 substrates have been identified, including those that regulate cell structure, cell cycle, and cell survival during apoptosis $(122,123)$.

Besides their role in apoptosis, caspases also have been reported to regulate non-apoptotic functions including cell proliferation, differentiation, morphogenesis, and migration in the immune system $(124,125)$. Caspase- 8 , in particular, has been well investigated and shown by 
the Lenardo group (126) to have a critical role in the activation of the NF- $\kappa B$ transcription factor after signaling through Ag receptors on B cells, T cells, and NK cells. According to this group (127), after TCR stimulation, PKC $\theta$ is activated and initiates caspase- 8 activity in the cytosol by forming a complex with CARD-MAGUK protein 1 (CARMA1), B-cell lymphoma 10 (BCL-10), and paracaspase mucosa-associated-lymphoid-tissue lymphoma-translocation gene 1 (MALT1) (the CBM complex). Activated caspase- 8 binds specifically to a ubiquitin ligase, tumor necrosis factor (TNF) receptor-associated factor 6 (TRAF6), which promotes the movement of the CBM complex to lipid rafts. This large signalosome of activated caspase-8, TRAF6, and the CBM complex within lipid rafts recruits I- $\mathrm{kB}$ kinase (IKK), leading to NF$\kappa \mathrm{B}$ activation and T-cell proliferation (127). Thus, caspase- 8 may play an essential role in NF$\kappa B$ pathway activation through TRAF6 (127). Consistent with these findings, mice with a Tcell-specific deletion of caspase-8 (tcasp8 KO mice) have defective T-cell proliferation (128). Tcasp8 KO mice also develop an age-dependent lethal lymphoproliferative disorder (129). Interestingly, despite the fact that both old and young tcasp8 KO T cells exhibit defective in vitro proliferation to various stimuli, a subset of T cells in old tcasp8 $\mathrm{KO}$ mice actively proliferate in the absence of any apparent stimulation. One explanation for this phenotype is that tcasp8 $\mathrm{KO} \mathrm{T}$ cells are resistant to CD95-induced apoptosis and thus accumulate in vivo with age. In addition to the role of caspase- 8 in TCR-induced NF- $\mathrm{KB}$ activation, caspase- 8 can cooperate with caspase- 10 and is required for double-stranded RNA-induced NF- $\mathrm{\kappa B}$ activation and inflammatory cytokine production after viral infection (130). Thus, caspase-8 may play a role in both TCR-induced and TLR-induced NF- $\mathrm{KB}$ activation.

Less is known about the non-apoptotic functions of caspases in B cells. Recently, mice with a B-cell-specific deletion of caspase-8 (bcasp8 KO mice) were described $(131,132)$. Unlike in T cells, caspase- 8 is not required for BCR-induced proliferation in B cells. Caspase- 8 is required, however, for signaling B cells through some TLRs, including TLR3 (receptor for double-stranded RNA) and TLR4 (LPS), but not for others like TLR9 (CpG DNA). TLR ligand binding initiates NF- $\mathrm{KB}$ activation (133). Indeed, in tcasp8 KO B cells, proliferation and transcriptional activation of NF- $\mathrm{kB}$ target genes IL-6, IFN- $\gamma$, TNF- $\alpha$, and IP-10 were defective in response to LPS (132). After TLR4 activation, caspase- 8 may be transiently recruited to $\mathrm{IKK} \alpha / \beta$, which is essential for the phosphorylation and degradation of I- $\kappa \mathrm{B}$. In the absence of caspase-8, the translocation of NF-kB-p65 into the nucleus was delayed in B cells in response to TLR3 or TLR4 stimulation $(126,132)$. Overall, these studies suggest that caspase-8 positively regulates some TLR pathways through NF- $\mathrm{kB}$ signaling in B cells.

In caspase-dependent apoptotic pathways, the majority of substrates, which include cell-cycle regulators, are preferentially cleaved by effector caspases. A KO mouse of the effector caspase, caspase-3 (casp3 KO), displays an interesting B-cell phenotype (134). Casp3 KO mice have splenomegaly with an increased total number of mature $\mathrm{B}$ cells but also have decreased numbers of B-lineage cells in the BM. This observation suggests that B-cell maturation is accelerated in casp3 KO mice. Indeed, casp3 KO BM-derived B cells show increased proliferation and cell division in response to IL-7, a cytokine essential for B-cell development (134). Splenic B cells from casp3 KO mice, in contrast to casp8 KO B cells, show increased proliferation in response to BCR, CD40, or TLR4 stimulation with or without IL-4. The cdk inhibitor $\mathrm{p} 21^{\mathrm{Cip} 1}$ in some cell types is cleaved by caspase- 3 during the early stage of apoptosis $(135,136)$. Although the function of $\mathrm{p} 21^{\mathrm{Cip} 1}$ as a cell cycle inhibitor has been well characterized, $\mathrm{p} 21^{\mathrm{Cip} 1}$ can also promote proliferation when associated with proliferating cell nuclear Ag (PCNA), an essential factor for DNA replication (137); $221^{\text {Cip1 }}$ also can promote cell cycle progression when associated with the Cdk4-cyclinD1 complex (138-141). In casp3 KO B cells, the levels of $\mathrm{p} 21^{\mathrm{Cip} 1}$ and PCNA are greatly increased and accompanied by elevated CDK2 and CDK4 kinase activity. Thus, caspase-3 may regulate B-cell proliferation and homeostasis by cleaving $\mathrm{p} 21^{\mathrm{Cip} 1}$. 


\section{Caspase- 6 regulates the entry and transit of B cells through the cell cycle}

We previously reported that the effector caspase, caspase-6, is required for cell cycle entry in human tonsil B cells (142). CD40- and CD180-induced human B-cell proliferation was strongly blocked by a caspase- 6 selective peptide inhibitor VEID. This strong inhibition accompanied decreased expression of proteins that promote cell cycle progression, including cyclin D2, cyclin A, cdk4 and phospho-Rb. After human B-cell activation, SATB1, a caspase-6 substrate, was cleaved concurrently with caspase- 6 activation. VEID treatment diminished both caspase- 6 activation and SATB 1 cleavage. Thus, we hypothesized that caspase- 6 regulates B-cell entry into $\mathrm{G}_{1}$, using SATB1 as a substrate (118). Consistent with this model, Werz et al. (143) showed that in human B cells, caspase-6 cleaves 5-lipoxygenase, which initiates the synthesis of bioactive leukotrienes from arachidonic acid. This cleavage correlated with proliferation of a Burkitt's lymphoma line BL41.

Caspase-6 (casp6) KO mice established by Zheng et al. (144) are grossly normal, breed with a Mendelian ratio, and do not show a striking apoptosis-related phenotype, being only slightly protected from anti-Fas/CD95-induced cell death $(144,145)$. To further analyze the function of caspase-6 in B cells, we examined B-cell activation in casp6 KO mice (146). First, we confirmed that caspase- 6 is cleaved after CD40 or TLR stimulation of WT B cells within 12 $\mathrm{h}$, correlating with the beginning of cell cycle entry. To examine each stage of the cell cycle precisely, we used P-Y staining (39). Using this system, we detected an ample number of large, activated, splenic $\mathrm{B}$ cells already in the $\mathrm{G}_{1}$ stage ex situ in casp6 $\mathrm{KO}$ mice. After activation, small resting $B$ cells derived from casp6 $\mathrm{KO}$ mice have enhanced entry into $\mathrm{G}_{1}$ but surprisingly do not enter $\mathrm{S}$ or $\mathrm{G}_{2} / \mathrm{M}$ phase more frequently compared with small resting WT B cells. Despite the fact that casp6 KO B cells show accelerated $\mathrm{G}_{1}$ entry, their proliferation was not increased, and, if anything, it was decreased (146). This suggested a possible defect in restriction point regulation, as discussed below. The viability and levels of spontaneous cell death of casp6 KO B cells were normal.

The results using stimulated casp6 KO mouse B cells differed from results with human B cells, where VEID blocked CD40-induced entry into $\mathrm{G}_{1}(142)$. The different effects on B-cell proliferation observed may be due to the fact that the VEID caspase inhibitor is selective but not specific (125). To test this possibility, we compared the effect of VEID on WT versus casp6 KO B cells. Graded doses of VEID inhibited the proliferation of both WT and casp6 KO B cells (authors' unpublished data), demonstrating that VEID affects more than caspase-6 in mouse $B$ cells. We also observed that $\mathrm{G}_{1}$ cells were increased when human $B$ cells were treated with VEID in the absence of stimulation, similar to ex situ casp6 KO B cells. Thus, we hypothesize that caspase- 6 negatively regulates the entry of quiescent $B$ cells from $G_{0}$ into the $\mathrm{G}_{1}$ stage of the cell cycle (Fig. 4).

During T-D humoral immune responses, Ag-specific B cells divide and form GCs. B cells later exit from GCs and terminally differentiate into plasma cells (PCs) in extrafollicular foci. Like activated casp6 KO B cells, PCs are arrested in the $\mathrm{G}_{1}$ phase of the cell cycle (147). Thus, we tested the possibility that the accelerated $\mathrm{G}_{1}$ entry of casp6 KO B cells did not translate into increased $\mathrm{S}$ phase entry due to a shift toward B-cell differentiation into PCs by $\mathrm{G}_{1}$ arrested casp6 KO B cells. Indeed, in vitro, PC formation was increased in casp6 KO B-cell cultures compared with WT B-cell cultures after various stimuli (146). Furthermore, in vivo $\mathrm{IgG}_{1}$, $\mathrm{IgG}_{2 \mathrm{a}}$, and $\mathrm{IgG}_{2 \mathrm{~b}}$ levels were already elevated in unimmunized casp6 $\mathrm{KO}$ mice. After immunization with OVA, $\mathrm{PC}$ and $\mathrm{Ag}$-specific $\mathrm{IgM}$ and $\mathrm{IgG}_{1}$ levels were also increased in casp6 KO mice compared with WT mice. Thus, caspase- 6 may regulate B-cell differentiation into PCs during humoral immune responses (Fig. 4). Consistent with this model, GC B-cell numbers were reduced in immunized casp6 KO mice, which had elevated Ag-specific Ig. Furthermore, PCs normally appear to have dramatically reduced levels of caspase- 6 compared with surface 
$\mathrm{IgM}^{+} \mathrm{B}$ cells (148), suggesting that reduction of caspase- 6 activity may be a normal and perhaps essential step during PC differentiation.

Identifying caspase-6 targets and determining the effect of caspase-6-mediated cleavage on their activity will be critical for understanding the mechanisms by which caspase- 6 regulates B-cell activation pathways. Some molecules reported to be caspase- 6 substrates include SATB1, p27 Kip1, Notch1, AP-2 $\alpha$, lamin A, and Akt (143,149-154). Rb, another potential caspase-6 substrate, regulates transition into S-phase by controlling the late $\mathrm{G}_{1}$-restriction point. Its phosphorylation and degradation allows cell cycle progression. $\mathrm{Rb}$ may also block apoptosis and is degraded by caspases in response to apoptotic stimuli (155). Unlike Rb levels in activated WT B cells, Rb protein did not decline in activated Casp6 KO B cells, and, if anything, increased (146). Because of this, the proportion of phosphorylated $\mathrm{Rb}$ was less in Casp6 KO B cells than in WT B cells. Casp6 KO B cells may retain more hypophosphorylated $\mathrm{Rb}$ capable of inhibiting E2F transcription factors, thereby preventing progression past the restriction point. Thus, despite an accelerated entry into $\mathrm{G}_{1}$, activated Casp6 KO B cells may not progress efficiently through $\mathrm{S}$ phase, because $\mathrm{Rb}$ is not downregulated normally in the absence of caspase- 6 , thus leading to an accumulation of $\mathrm{G}_{1}$ stage $\mathrm{B}$ cells in casp6 $\mathrm{KO}$ mice (Fig. 4B). Inefficient transit through the cell cycle may favor processes leading to cell differentiation. Indeed, $\mathrm{Rb}$ has been implicated in promoting terminal differentiation of several cell types (156). Microarray analyses showed that $\mathrm{Rb}$ is strongly expressed in human PCs but not in malignant PCs $(148,157)$. These studies suggest that in PCs, the machinery promoting cell cycle progression and proliferation is downregulated in correlation with differentiation. Interestingly, the elevated levels of $\mathrm{Rb}$ in PCs are opposite to the reduced expression of caspase-6 in PCs (148). Thus, in the absence of caspase-6, elevated levels of Rb may promote PC differentiation at the expense of proliferation (Fig. 4B). Additionally, caspases themselves can affect cell differentiation (124). Caspase-3 activity is required for maturation of DCs (158). Although caspase-6 is greatly reduced in PCs (157), it remains unclear what suppressor of $\mathrm{G}_{1}$ entry caspase-6 targets in activated B cells (Fig. 4A). However, caspase-6 most likely regulates $B$ cells already in $G_{1}$ by targeting $R b$, which blocks $B$ cells from going into $S$ phase and may promote the differentiation of B cells into PCs. Thus, we hypothesize that caspase- 6 controls the balance between $\mathrm{B}$-cell proliferation and differentiation through the regulation $\mathrm{B}-$ cell entry into the $\mathrm{G}_{1}$ stage of the cell cycle (Fig. 4A).

Caspases have a role in B-cell development. As mentioned in casp3 KO mice, B-cell development is accelerated at the stage where B-cell precursors develop into immature B cells. We found that adult casp6 KO and WT mice have similar numbers of BM and splenic B-cell subsets. However, in 1-week-old casp6 KO mice, B-cell development was accelerated: the absolute cell numbers of all B-cell subsets in 1-week-old casp6 KO mice were markedly increased compared with age-matched WT mice (C. Watanabe et al., manuscript in preparation). However, as they became adults, their B-cell subsets became normal. B-1 B cells develop early in life in the fetal liver and are found principally in the peritoneal cavity and gutassociated lymphoid tissues in adults (159, C. Watanabe et al., manuscript in preparation). In 3-week-old casp6 KO mice, peritoneal B-1a B cells, which express B220, CD5, and CD11b, were significantly increased compared with WT mice, but again this population was normal in adult casp6 KO mice.

These results suggested that very early B-cell development may be accelerated in the absence of caspase-6. IL-7 is an essential cytokine for both B-cell and T-cell development. During Bcell development in the BM, IL-7 is required for the development of mature B cells from common lymphoid progenitors (CLPs). In particular, proB cells in the BM proliferate in response to IL-7 and become preB cells (160). Similar to casp3 KO BM B cells (134), casp6 KO BM B cells displayed hyperproliferation in response to graded doses of IL-7 (C. Watanabe et al., manuscript in preparation). Furthermore, the lineage negative CLP population derived 
from casp6 KO mice developed into immature B cells faster than WT CLPs in an IL-7dependent manner. Because IL-7 induces caspase- 3 and caspase- 8 cleavage in proliferating recent thymic emigrants (161), we are currently defining what elements in the IL-7-induced Jak-STAT pathway are targeted by caspase- 6 . We do not fully understand how the accelerated B-cell development in casp6 KO mice is attenuated as they become adults. Further investigation of the caspase targets in IL-7 signaling will help to clarify the roles caspase- 6 plays during early B-cell development.

As discussed above, caspase- 6 plays a unique role in balancing proliferation and differentiation in $B$ cells, by regulating both entry into $G_{1}$ and the $R b$-dependent restriction point. Caspase- 6 also plays a role in early B-cell development. The mechanism underlying caspase-6's modification of early B-cell development may differ from how it regulates mature B cells. The substrates cleaved by caspase- 6 in mature B cells may differ from the substrates targeted during early B-cell development. Little is known regarding which substrates may be cleaved by caspase family members after lymphocyte activation, but it is likely that the caspase cascade triggered in activated lymphocytes differs from that triggered in apoptotic cells.

\section{Concluding comments}

Dysregulation of B-cell proliferation or antibody production can lead to cancers or autoimmune diseases. As a result, the steps leading to B-cell division or maturation must be carefully regulated. In this review, we have discussed Bam 32 and Bim, which promote B-cell entry into the cell cycle, and CD22, Nox, and caspase 6, which retard cell cycle entry in B cells (Fig. 1). Some of these regulators, most notably Bam 32 and Nox, may function by competing for the same key signaling elements (Fig. 2). Likewise, Bim and Bcl-2 may compete in B cells and other cells for the same upstream elements such as IP3 receptors or proteins associated with mitochondria (112).

Other regulators appear to function at different points in B-cell activation pathways. Both Bam32 and Bim promote B-cell entry into the $\mathrm{G}_{1}$ stage of the cell cycle and regulate downstream expression of $\mathrm{p} 27^{\mathrm{kip} 1}$; nevertheless, they are likely to mediate cell cycle entry differently, because Bam32 primarily affects BCR signaling, whereas Bim affects both BCR and LPS signaling pathways $(32,112)$. Although Nox and caspase- 6 both retard B cells from entering $\mathrm{G}_{1}$, they too are likely to act via different mechanisms. Caspase- 6 targets CD40 and TLR-dependent activation pathways, while Nox-dependent ROS influence primarily BCR signaling $(53,146)$. Besides sharing similar enhanced entry into $\mathrm{G}_{1}$, these two KO B cells share little else between their phenotypes. Casp6 KO B cells do not progress to S-phase; instead, absence of caspase- 6 activity shifts $\mathrm{G}_{1}$ B cells toward differentiation into PCs after CD40 or TLR stimulation (146). In contrast, increased $\mathrm{G}_{1}$ entry in gp9 $91^{\text {phox }} \mathrm{KO} \mathrm{B}$ cells is accompanied by progression through the cell cycle and leads to more proliferation. Additionally, while gp91 phox $\mathrm{B}$ cells demonstrate delayed $\mathrm{p} 27^{\mathrm{Kip} 1}$ downregulation after activation, activated casp6 KO B cells downregulate $\mathrm{p} 27^{\mathrm{Kip} 1}$ normally $(53,146)$. This observation suggests caspase- 6 and Nox modulate distinct biochemical pathways in B cells.

Unlike caspase-6 regulation of B cells, CD22-mediated inhibition of B-cell division appears to be restricted to BCR-induced activation; indeed, LPS-induced B-cell proliferation may be positively regulated by CD22 (25). Interestingly, mice missing a promoter of cell cycle entry, $\mathrm{Bim}$, share features with mice missing CD22: both CD22 KO and Bim KO mice have reduced numbers of MZ B cells $(69,100,102-104)$. However, CD22 KO and Bim KO B cells differ in other ways: CD22 KO B cells have elevated BCR-induced release of $\left[\mathrm{Ca}^{2+}\right]_{i}(25)$, while Bim $\mathrm{KO}$ have reduced $\left[\mathrm{Ca}^{2+}\right]_{\mathrm{i}}$ release (112). CD22 KO B cells turnover faster than WT B cells in vivo, while Bim KO B cells survive longer (162). Alone in culture or with DCs, CD22 KO B cells die more readily than WT B cells (69), while Bim KO B cells survive longer in culture 
$(99,100)$. Both CD22 KO and Bim KO B cells have defects in cell cycle entry, which conceivably could put MZ B-cell development at risk, because they may normally be in cell cycle as they enter MZs (163). Alternatively, the sustained survival of splenic B cells in Bim $\mathrm{KO}$ and Bcl-2 Tg mice in effect leads to a similar program induced by pronounced BCR signals which favor FO B cells over MZ B cells (85).

Understanding more about how B-cell proliferation is regulated will be helpful for designing new approaches for treating B-cell-associated diseases. Although great strides have been made in the treatment of autoimmune diseases with B-cell depletion therapies, much remains to be learned $(164,165)$. The best approach for removing pathogenic B cell Ag-presenting cells or auto-antibody-producing cells is not yet clear. Ideally, one would like to have therapies that are selective for B-cell subpopulations. Selective combination therapies are promising. A combination of antibody-based B-cell depletion therapy along with other antibody or chemotherapeutic agents in particular appears to be effective for patients with chronic lymphocytic leukemia $(166,167)$. As more is learned about what regulates transit of B-cell subsets through the cell cycle and their decisions to divide, survive, or differentiate, it should be possible to thoughtfully design highly selective drugs that target pathogenic B-cell subsets.

\section{Acknowledgements}

This work was supported by NIH grants GM37905, AI44250, AI52203, and DE16381, by the Cancer Research Institute Predoctoral Emphasis Pathway in Tumor Immunology training grant (S. R.) and by the Research Fellowship of Japan Society for the Promotion of Science (C. W.).

\section{References}

1. Cambier JC, Gauld SB, Merrell KT, Vilen BJ. B-cell anergy: from transgenic models to naturally occurring anergic B cells? Nat Rev Immunol 2007;7:633-643. [PubMed: 17641666]

2. Niiro H, Clark EA. Regulation of B-cell fate by antigen-receptor signals. Nat Rev Immunol 2002;25:945-956. [PubMed: 12461567]

3. Callard R, Hodgkin P. Modeling T- and B-cell growth and differentiation. Immunol Rev 2007;216:119129. [PubMed: 17367338]

4. Allen CD, Okada T, Cyster JG. Germinal-center organization and cellular dynamics. Immunity 2007;2:190-202. [PubMed: 17723214]

5. Gerondakis S, Grumont RJ, Banerjee A. Regulating B-cell activation and survival in response to TLR signals. Immunol Cell Biol 2007;85:471-475. [PubMed: 17637697]

6. Dal Porto JM, Gauld SB, Merrell KT, Mills D, Pugh-Bernard AE, Cambier J. B cell antigen receptor signaling 101. Mol Cell 2004;41:599-613.

7. Wu JN, Koretzky GA. The SLP-76 family of adaptor proteins. Semin Immunol 2004;16:379-393. [PubMed: 15541653]

8. Buhl AM, Cambier JC. Co-receptor and accessory regulation of B-cell antigen receptor signal transduction. Immunol Rev 1997;160:127-138. [PubMed: 9476671]

9. Del Nagro CJ, Otero DC, Anzelon AN, Omori SA, Kolla RV, Rickert RC. CD19 QJ;function in central and peripheral B-cell development. Immunol Res 2005;31:119-131. [PubMed: 15778510]

10. Nitschke L. The role of CD22 and other inhibitory co-receptors in B-cell activation. Curr Opin Immunol 2005;17:290-297. [PubMed: 15886119]

11. Sherr CJ, Roberts JM. CDK inhibitors: positive and negative regulators of G1-phase progression. Genes Dev 1999;13:1501-1512. [PubMed: 10385618]

12. Sun A, Bagella L, Tutton S, Romano G, Giordano A. From G0 to S phase: a view of the roles played by the retinoblastoma $(\mathrm{Rb})$ family members in the Rb-E2F pathway. J Cell Biochem 2007;102:14001404. [PubMed: 17979151]

13. Huang H, Tindall DJ. Commentary. Dynamic FoxO transcription factors. J Cell Sci 2007;120:2479_ 2487. [PubMed: 17646672] 
14. Arellano M, Moreno S. Regulation of CDK/cyclin complexes during the cell cycle. Int J Biochem Cell Biol 1997;29:559-573. [PubMed: 9363633]

15. Li WQ, Jiang Q, Aleem E, Kaldis P, Khaled AR, Durum SK. IL-7 promotes T cell proliferation through destabilization of p27Kip1. J Exp Med 2006;203:573-582. [PubMed: 16492801]

16. Stahl M, et al. The forkhead transcription factor FoxO regulates transcription of p27Kip1 and Bim in response to IL-2. J Immunol 2002;168:5024-5031. [PubMed: 11994454]

17. Schmidt M, et al. Cell cycle inhibition by FoxO forkhead transcription factors involves downregulation of cyclin D. Mol Cell Biol 2002;22:7842-7852. [PubMed: 12391153]

18. Yusuf I, Zhu X, Kharas MG, Chen J, Fruman DA. Brief report. Optimal B-cell proliferation requires phosphoinositide 3-kinase-dependent inactivation of FOXO transcription factors. Blood 2004;104:784-787. [PubMed: 15069012]

19. Grumont RJ, Strasser A, Gerondakis S. B cell growth is controlled by phosphoinositide 3-kinasedependent induction of Rel/NFKB regulated c-myc transcription. Mol Cell 2002;10:1283-1294. [PubMed: 12504005]

20. Piatelli MJ, et al. Phosphatidylinositol 3-kinase-dependent mitogen-activated protein/extracellular signal-regulated kinase kinase $1 / 2$ and NF-kappa B signaling pathways are required for B cell antigen receptor-mediated cyclin D2 induction in mature B cells. J Immunol 2004;172:2753-2762. [PubMed: 14978074]

21. Chiles TC. Regulation and function of cyclin D2 in B lymphocyte subsets. J Immunol 2004;173:29012907. [PubMed: 15322145]

22. Solvason N, et al. Cyclin D2 is essential for BCR-mediated proliferation and CD5 B cell development. Int Immunol 2000;12:631-638. [PubMed: 10784609]

23. Lam EW, Glassford J, Banerji L, Thomas NSB, Sicinski P, Klaus GGB. Cyclin D3 compensates for loss of cyclin D2 in mouse B lymphocytes activated via the antigen receptor and CD40. J Biol Chem 2000;275:3479-3484. [PubMed: 10652342]

24. Carman JA, Wechsler-Reya RJ, Monroe JG. Immature stage B cells enter but do not progress beyond the early G1 stage of the cell cycle in response to antigen receptor signaling. J Immunol 1996;156:4562-4569. [PubMed: 8648097]

25. Otipoby KL, et al. CD22 regulates thymus-independent responses and the lifespan of B cells. Nature 1996;384:634-637. [PubMed: 8967951]

26. Niiro H, Clark EA. Branches of the B cell antigen receptor pathway are directed by protein conduits Bam32 and Carma1. Immunity 2003;19:637-640. [PubMed: 14614850]

27. Dowler S, Currie RA, Downes CP, Alessi DR. DAPP1: a dual adaptor for phosphotyrosine and 3phosphoinositides. Biochem J 1999;342:7-12. [PubMed: 10432293]

28. Marshall AJ, et al. A novel B lymphocyte-associated adaptor protein, Bam32, regulates antigen receptor signaling downstream of phosphatidylinositol 3-kinase. J Exp Med 2000;191:1319-1332. [PubMed: 10770799]

29. Marshall AJ, Krahn AK, Ma K, Duronio V, Hou S. TAPP1 and TAPP2 are targets of phosphatidylinositol 3-kinase signaling in B cells: sustained plasma membrane recruitment triggered by the B-cell antigen receptor. Mol Cell Biol 2002;22:5479-5491. [PubMed: 12101241]

30. Niiro H, Maeda A, Kurosaki T, Clark EA. The B lymphocyte adaptor molecule of $32 \mathrm{kD}$ (Bam32) regulates B cell antigen receptor signaling and cell survival. J Exp Med 2002;195:143-149. [PubMed: 11781373]

31. Allam A, Niiro H, Clark EA, Marshall AJ. The adaptor protein Bam32 regulates Rac1 activation and actin remodeling through a phosphorylation-dependent mechanism. J Biol Chem 2004;279:3977539782. [PubMed: 15247305]

32. Niiro H, Allam A, Stoddart A, Brodsky FM, Marshall AJ, Clark EA. The B lymphocyte adaptor molecule of 32 kilodaltons (Bam32) regulates B cell antigen receptor internalization. J Immunol 2004;173:5601-5609. [PubMed: 15494510]

33. Kaibuchi K, Kuroda S, Amano M. Regulation of the cytoskeleton and cell adhesion by the Rho family GTPases in mammalian cells. Annu Rev Biochem 1999;68:459-486. [PubMed: 10872457]

34. Krahn AK, Ma K, Hou S, Duronio V, Marshall AJ. Two distinct waves of membrane-proximal B cell antigen receptor signaling differentially regulated by Src homology 2-containing inositol polyphosphate 5-phosphatase. J Immunol 2004;172:331-339. [PubMed: 14688341] 
35. March ME, Ravichandran K. Regulation of the immune response by SHIP. Semin Immunol 2002;14:37-47. [PubMed: 11884229]

36. Han A, Saijo K, Mecklenbrauker I, Tarakhovsky A, Nussenzweig MC. Bam32 links the B cell receptor to ERK and JNK and mediates B cell proliferation but not survival. Immunity 2003;19:621-632. [PubMed: 14563325]

37. Fournier E, et al. The B cell SH2/PH domain-containing adaptor Bam32/DAPP1 is required for T cell-independent II antigen responses. Curr Biol 2003;13:1858-1866. [PubMed: 14588241]

38. Marshall AJ, Zhang T, Al-Alwan M. Regulation of B-lymphocyte activation by the PH domain adaptor protein Bam32/DAPP1. Biochem Soc Trans 2007;35:181-182. [PubMed: 17371232]

39. Schmid I, Cole SW, Korin YD, Zack JA, Giorgi JV. Detection of cell cycle subcompartments by flow cytometric estimation of DNA-RNA content in combination with dual-color immunofluorescence. Cytometry 2000;39:108-116. [PubMed: 10679728]

40. Clark EA, Richards S, Santos L. Regulation of B cell entry into cell cycle by superoxide and CD22. Biology of B Cells in Health and Disease. Keystone Symposia 2007;173:77.abstract

41. Monteiro HP, Stern A. Redox modulation of tyrosine phosphorylation-dependent signal transduction pathways. Free Radic Biol Med 1996;21:323-333. [PubMed: 8855443]

42. Chiarugi P, Cirri P. Redox regulation of protein tyrosine phosphatases during receptor tyrosine kinase signal transduction. Trends Biochem Sci 2003;28:509-514. [PubMed: 13678963]

43. Rhee SG, Kang SW, Jeong W, Chang TS, Yang KS, Woo HA. Intracellular messenger function of hydrogen peroxide and its regulation by peroxiredoxins. Curr Opin Cell Biol 2005;17:183-189. [PubMed: 15780595]

44. Meng TC, Fukada T, Tonks NK. Reversible oxidation and inactivation of protein tyrosine phosphatases in vivo. Mol Cell 2002;9:387-399. [PubMed: 11864611]

45. Reth M. Hydrogen peroxide as second messenger in lymphocyte activation. Nat Immunol 2002;3:1129-1134. [PubMed: 12447370]

46. Sumimoto H, Miyano K, Takeya R. Molecular composition and regulation of the Nox family NAD (P)H oxidases. Biochem Biophys Res Commun 2005;338:677-686. [PubMed: 16157295]

47. Kanai F, et al. The PX domains of p47phox and p40phox bind to lipid products of PI(3)K. Nat Cell Biol 2001;3:675-678. [PubMed: 11433300]

48. Morel F, et al. The O2- generating oxidase of B lymphocytes: Epstein-Barr virus-immortalized B lymphocytes as a tool for the identification of defective components of the oxidase in chronic granulomatous disease. Biochim Biophys Acta 1993;1182:101-109. [PubMed: 8394141]

49. Schieven GL, Kirihara JM, Burg DL, Geahlen RL, Ledbetter JA. p72syk tyrosine kinase is activated by oxidizing conditions that induce lymphocyte tyrosine phosphorylation and $\mathrm{Ca} 2+$ signals. J Biol Chem 1993;268:16688-16692. [PubMed: 8344947]

50. Singh DK, Kumar D, Siddiqui Z, Basu SK, Kumar V, Rao KV. The strength of receptor signaling is centrally controlled through a cooperative loop between $\mathrm{Ca} 2+$ and an oxidant signal. Cell 2005;121:281-293. [PubMed: 15851034]

51. Tonks NK. Redox redux: revisiting PTPs and the control of cell signaling. Cell 2005;121:667-670. [PubMed: 15935753]

52. Pollock JD, et al. Mouse model of X-linked chronic granulomatous disease, an inherited defect in phagocyte superoxide production. Nat Genet 1995;9:202-209. [PubMed: 7719350]

53. Richards S, Clark EA. Superoxide production influences cell cycle entry downstream of BCR ligation. Biology of B Cells in Health and Disease. Keystone Symposia 2007;358:107.abstract

54. Hibbs ML, et al. Sustained activation of Lyn tyrosine kinase in vivo leads to autoimmunity. J Exp Med 2002;196:1593-1604. [PubMed: 12486102]

55. Chan VW, Meng F, Soriano P, DeFranco AL, Lowell CA. Characterization of the B lymphocyte populations in Lyn-deficient mice and the role of Lyn in signal initiation and down-regulation. Immunity 1997;7:69-81. [PubMed: 9252121]

56. Clark EA, Ledbetter JA. How B and T cells talk to each other. Nature 1994;367:425-428. [PubMed: 8107800]

57. Mellman I, Steinman RM. Dendritic cells: specialized and regulated antigen processing machines. Cell 2001;106:255-258. [PubMed: 11509172] 
58. Kapsenberg ML. Dendritic-cell control of pathogen-driven T-cell polarization. Nat Rev Immunol 2003;367:984-993. [PubMed: 14647480]

59. Dubois B, et al. Critical role of IL-12 in dendritic cell-induced differentiation of naive B lymphocytes. J Immunol 1998;161:2223-2231. [PubMed: 9725215]

60. Balazs M, Martin F, Zhou T, Kearney J. Blood dendritic cells interact with splenic marginal zone B cells to initiate T-independent immune responses. Immunity 2002;17:341-352. [PubMed: 12354386]

61. Litinskiy MB, et al. DCs induce CD40-independent immunoglobulin class switching through BLyS and APRIL. Nat Immunol 2002;3:822-829. [PubMed: 12154359]

62. Craxton A, Magaletti D, Ryan EJ, Clark EA. Macrophage- and dendritic cell-dependent regulation of human B-cell proliferation requires the TNF family ligand BAFF. Blood 2003;101:4464-4471. [PubMed: 12531790]

63. Hanada T, et al. Suppressor of cytokine signaling-1 is essential for suppressing dendritic cell activation and systemic autoimmunity. Immunity 2003;19:437-450. [PubMed: 14499118]

64. Jego G, Palucka AK, Blanck JP, Chalouni C, Pascual V, Banchereau J. Plasmacytoid dendritic cells induce plasma cell differentiation through type I interferon and interleukin 6. Immunity 2003;19:225234. [PubMed: 12932356]

65. Pinchuk LM, Klaus SJ, Magaletti DM, Pinchuk GV, Norsen JP, Clark EA. Functional CD40 ligand expressed by human blood dendritic cells is up-regulated by CD40 ligation. J Immunol 1996;157:4363-4370. [PubMed: 8906811]

66. Wykes M, MacPherson G. Dendritic cell-B-cell interaction: dendritic cells provide B cells with CD40independent proliferation signals and CD40-dependent survival signals. Immunology 2000;100:1352. [PubMed: 10809952]

67. Bergtold A, Desai DD, Gavhane A, Clynes R. Cell surface recycling of internalized antigen permits dendritic cell priming of B cells. Immunity 2005;23:503-514. [PubMed: 16286018]

68. Qi H, Egen JG, Huang AY, Germain RN. Extrafollicular activation of lymph node B cells by antigenbearing dendritic cells. Science 2006;312:1672-1676. [PubMed: 16778060]

69. Santos L, Draves KE, Boton M, Grewal PK, Marth JD, Clark EA. Dendritic cell-dependent inhibition of B cell proliferation requires CD22. J Immunol 2008;180:4561-4569. [PubMed: 18354178]

70. Hawiger D, et al. Dendritic cells induce peripheral T cell unresponsiveness under steady state conditions in vivo. J Exp Med 2001;194:769-779. [PubMed: 11560993]

71. Steinman RM, Hawiger D, Nuusenzweig MC. Tolerogenic dendritic cells. Annu Rev Immunol 2003;21:685-711. [PubMed: 12615891]

72. Law CL, et al. CD22 associates with protein tyrosine phosphatase 1C, Syk, and phospholipase Cgamma(1) upon B cell activation. J Exp Med 1996;183:547-560. [PubMed: 8627166]

73. Cornall RJ, Goodnow CC, Cyster JG. Regulation of B cell antigen receptor signaling by the Lyn/ CD22/SHP1 pathway. Curr Top Microbiol Immunol 1999;244:57-68. [PubMed: 10453649]

74. Nitschke L, Tsubata T. Molecular interactions regulate BCR signal inhibition by CD22 and CD72. Trends Immunol 2004;25:543-550. [PubMed: 15364057]

75. Hennet T, Chui D, Paulson JC, Marth JD. Immune regulation by the ST6Gal sialyltransferase. Proc Natl Acad Sci USA 1998;95:4504-4509. [PubMed: 9539767]

76. Law CL, Aruffo A, Chandran KA, Doty RT, Clark EA. Ig domains 1 and 2 of murine CD22 constitute the ligand-binding domain and bind multiple sialylated ligands expressed on B and T cells. J Immunol 1995;155:3368-3376. [PubMed: 7561031]

77. Cyster JG, Goodnow CC. Tuning antigen receptor signaling by CD22: integrating cues from antigens and the microenvironment. Immunity 1997;6:509-517. [PubMed: 9175829]

78. Grewal PK, et al. ST6Gal-I restrains CD22-dependent antigen receptor endocytosis and Shp-1 recruitment in normal and pathogenic immune signaling. Mol Cell Biol 2006;26:4970-4981. [PubMed: 16782884]

79. Crocker PR, Paulson JC, Varki A. Siglecs and their roles in the immune system. Nat Rev Immunol 2007;7:255-266. [PubMed: 17380156]

80. Poe JC, et al. CD22 regulates B lymphocyte function in vivo through both ligand-dependent and ligand-independent mechanisms. Nat Immunol 2004;5:1078-1087. [PubMed: 15378059] 
81. Jin PL, McLean PA, Neel BG, Wortis HH. Sialic acid binding domains of CD22 are required for negative regulation of B cell receptor signaling. J Exp Med 2002;195:1199-1205. [PubMed: 11994425]

82. Kelm S, Gerlach J, Grossmer R, Danzer CP, Nitschke L. The ligand-binding domain of CD22 is needed for inhibition of the $\mathrm{B}$ cell receptor signal, as demonstrated by a novel human CD22-specific inhibitor compound. J Exp Med 2002;195:1207-1213. [PubMed: 11994426]

83. Han S, Collins BE, Bengtson P, Paulson JC. Homomultimeric complexes of CD22 in B cells revealed by protein-glycan cross-linking. Nat Chem Biol 2005;155:93-97. [PubMed: 16408005]

84. Collins BE, Smith BA, Bengtson P, Paulson JC. Ablation of CD22 in ligand-deficient mice restores B cell receptor signaling. Nat Immunol 2006;7:199-206. [PubMed: 16369536]

85. Pillai S, Cariappa A, Moran ST. Positive selection and lineage commitment during peripheral Blymphocyte development. Immunol Rev 2004;197:206-218. [PubMed: 14962197]

86. Casola S, et al. B cell receptor signal strength determines B cell fate. Nat Immunol 2004;5:317-327. [PubMed: 14758357]

87. Carsetti R, Kohler G, Lamers MC. Transitional B cells are the target of negative selection in the B cell compartment. J Exp Med 1995;181:2129-2140. [PubMed: 7760002]

88. Waldschmidt TJ, Noelle RJ. Long live the mature B cell - a baffling mystery resolved. Science 2001;293:2012-2013. [PubMed: 11557866]

89. Collins BE, Blixt O, DeSieno AR, Bovin N, Marth JD, Paulson JC. Masking of CD22 by cis ligands does not prevent redistribution of CD22 to sites of cell contact. Proc Natl Acad Sci USA 2004;101:6104-6109. [PubMed: 15079087]

90. Leprince C, Draves KE, Geahlen RL, Ledbetter JA, Clark EA. CD22 associates with the human surface IgM-B-cell antigen receptor complex. Proc Natl Acad Sci USA 1993;90:3236-3240. [PubMed: 8475064]

91. Tuscano JM, Riva A, Toscano SN, Tedder TF, Kehrl JH. CD22 cross-linking generates B-cell antigen receptor-independent signals that activate the JNK/SAPK signaling cascade. Blood 1999;94:13821392. [PubMed: 10438726]

92. Lanoue A, Batista FD, Stewart M, Neuberger MS. Interaction of CD22 with alpha2,6-linked sialoglycoconjugates: innate recognition of self to dampen B cell autoreactivity? Eur J Immunol 2002;32:348-355. [PubMed: 11807774]

93. Strasser A. The role of BH3-only proteins in the immune system. Nat Rev Immunol 2005;5:189-200. [PubMed: 15719025]

94. Opferman JT, Korsmeyer SJ. Apoptosis in the development and maintenance of the immune system. Nat Immunol 2003;4:410-415. [PubMed: 12719730]

95. Chen L, et al. Differential targeting of prosurvival Bcl-2 proteins by their BH3-only ligands allows complementary apoptotic function. Mol Cell 2005;17:393-403. [PubMed: 15694340]

96. Letai A, Bassik MC, Walensky LD, Sorcinelli MD, Weiler S, Korsmeyer SJ. Distinct BH3 domains either sensitize or activate mitochondrial apoptosis, serving as prototype cancer therapeutics. Cancer Cell 2002;2:183-192. [PubMed: 12242151]

97. Bouillet $\mathrm{P}$, et al. Proapoptotic Bcl-2 relative Bim required for certain apoptotic responses, leukocyte homeostasis, and to preclude autoimmunity. Science 1999;286:1735-1738. [PubMed: 10576740]

98. Bouillet $\mathrm{P}$, et al. BH3-only Bcl-2 family member Bim is required for apoptosis of autoreactive thymocytes. Nature 2002;415:922-926. [PubMed: 11859372]

99. Enders A, Bouillet P, Puthalakath H, Xu Y, Tarlinton DM, Strasser A. Loss of the pro-apoptotic BH3only Bcl-2 family member Bim inhibits BCR stimulation-induced apoptosis and deletion of autoreactive B cells. J Exp Med 2003;198:1119-1126. [PubMed: 14517273]

100. Craxton A, Draves KE, Gruppi A, Clark EA. BAFF regulates B cell survival by down-regulating the BH3-only family member Bim via the ERK pathway. J Exp Med 2005;202:1363-1374. [PubMed: 16301744]

101. Lesley R, et al. Reduced competitiveness of autoantigen-engaged B cells due to increased dependence on BAFF. Immunity 2004;20:441-453. [PubMed: 15084273]

102. Goodyear CS, Corr M, Sugiyama F, Boyle DL, Silverman GJ. Bim is required for super-antigenmediated B cell death. J Immunol 2007;178:2636-2640. [PubMed: 17312102] 
103. Brunner C, Marinkovic D, Klein J, Samardzic T, Nitschke L, Wirth T. B cell-specific transgenic expression of Bcl2 rescues early B lymphopoiesis but not B cell responses in BOB. 1/OBF.1deficient mice. J Exp Med 2003;197:1205-1211. [PubMed: 12732662]

104. Tardivel A, et al. The anti-apoptotic factor Bcl-2 can functionally substitute for the B cell survival but not for the marginal zone B cell differentiation activity of BAFF. Eur J Immunol 2004;34:509_ 518. [PubMed: 14768056]

105. Bouillet P, Cory S, Zhang LC, Strasser A, Adams JM. Degenerative disorders caused by Bcl-2 deficiency prevented by loss of its BH3-only antagonist Bim. Dev Cell 2001;197:645-653. [PubMed: 11709185]

106. Bouillet P, Robati M, Bath M, Strasser A. Polycystic kidney disease prevented by transgenic RNA interference. Cell Death Differ 2005;12:831-833. [PubMed: 15818405]

107. O'Reilly LA, Huang DC, Strasser A. The cell death inhibitor Bcl-2 and its homologues influence control of cell cycle entry. EMBO J 1996;15:6979-6990. [PubMed: 9003774]

108. O'Reilly LA, Harris AW, Tarlinton DM, Corcoran LM, Strasser A. Expression of a bcl-2 transgene reduces proliferation and slows turnover of developing B lymphocytes in vivo. J Immunol 1997;159:2301-2311. [PubMed: 9278319]

109. Linette GP, Li Y, Roth K, Korsmeyer SJ. Cross talk between cell death and cell cycle progression: BCL-2 regulates NFAT-mediated activation. Proc Natl Acad Sci USA 1996;93:9545-9552. [PubMed: 8790367]

110. Vairo G, et al. Bcl-2 retards cell cycle entry through p27(Kip1), pRB relative p130, and altered E2F regulation. Mol Cell Biol 2000;20:4745-4753. [PubMed: 10848600]

111. Greider C, Chattopadhyay A, Parkhurst C, Yang E. BCL-x(L) and BCL2 delay Myc-induced cell cycle entry through elevation of p27 and inhibition of G1 cyclin-dependent kinases. Oncogene 2002;21:7765-7775. [PubMed: 12420213]

112. Craxton A, Draves KE, Clark EA. Bim promotes BCR-induced entry of B cells into the cell cycle. Eur J Immunol 2007;37:2715-2722. [PubMed: 17705137]

113. Morishima N, Nakanishi K, Tsuchiya K, Shibata T, Seiwa E. Translocation of Bim to the endoplasmic reticulum (ER) mediates ER stress signaling for activation of caspase-12 during ER stress-induced apoptosis. J Biol Chem 2004;279:50375-50381. [PubMed: 15452118]

114. Davis MC, Distelhorst CW. Live free or die: an immature T cell decision encoded in distinct Bcl-2 sensitive and insensitive Ca2+ signals. Cell Cycle 2006;5:1171-1174. [PubMed: 16721059]

115. Cante-Barrett K, Gallo EM, Winslow MM, Crabtree GR. Thymocyte negative selection is mediated by protein kinase $\mathrm{C}$-and $\mathrm{Ca} 2+$-dependent transcriptional induction of Bim of cell death. $\mathrm{J}$ Immunol 2006;176:2299-2306. [PubMed: 16455986]

116. Marechal Y, et al. Inositol 1,3,4,5-tetrakisphosphate controls proapoptotic Bim gene expression and survival in B cells. Proc Natl Acad Sci USA 2007;104:13978-13983. [PubMed: 17709751]

117. Alnemri ES, et al. Human ICE/CED-3 protease nomenclature. Cell 1996;87:171. [PubMed: 8861900]

118. Graves JD, Craxton A, Clark EA. Modulation and function of caspase pathways in B lymphocytes. Immunol Rev 2004;197:129-146. [PubMed: 14962192]

119. Kuranaga E, Miura M. Nonapoptotic functions of caspases: caspases as regulatory molecules for immunity and cell-fate determination. Trends Cell Biol 2007;17:135-144. [PubMed: 17275304]

120. Abraham MC, Shaham S. Death without caspases, caspases without death. Trends Cell Biol 2004;14:184-193. [PubMed: 15066636]

121. Wang ZB, Liu YQ, Cui YF. Pathways to caspase activation. Cell Biol Int 2005;29:489-496. [PubMed: 15939633]

122. Luthi AU, Martin SJ. The CASBAH: a searchable database of caspase substrates. Cell Death Differ 2007;14:641-650. [PubMed: 17273173]

123. Timmer JC, Salvesen GS. Caspase substrates. Cell Death Differ 2007;14:66-72. [PubMed: 17082814]

124. Lamkanfi M, Festjens N, Declercq W, Vanden Berghe T, Vandenabeele P. Caspases in cell survival, proliferation and differentiation. Cell Death Differ 2007;14:44-55. [PubMed: 17053807] 
125. Siegel RM. Caspases at the crossroads of immune-cell life and death. Nat Rev Immunol 2006;6:308317. [PubMed: 16557262]

126. $\mathrm{Su} \mathrm{H}$, et al. Requirement for caspase- 8 in NF-kappaB activation by antigen receptor. Science 2005;305:1465-1468. [PubMed: 15746428]

127. Bidere N, Snow AL, Sakai K, Zheng L, Lenardo MJ. Caspase-8 regulation by direct interaction with TRAF6 in T cell receptor-induced NF-kappaB activation. Curr Biol 2006;16:1666-1671. [PubMed: 16920630]

128. Salmena L, et al. Essential role for caspase 8 in T-cell homeostasis and T-cell-mediated immunity. Genes Dev 2003;17:883-895. [PubMed: 12654726]

129. Salmena L, Hakem R. Caspase- 8 deficiency in T cells leads to a lethal lymphoinfiltrative immune disorder. J Exp Med 2005;202:727-732. [PubMed: 16157684]

130. Takahashi K, Kawai T, Kumar H, Sato S, Yonehara S, Akira S. Roles of caspase-8 and caspase-10 in innate immune responses to double-stranded RNA. J Immunol 2006;176:4520-4524. [PubMed: 16585540]

131. Beisner DR, Ch'en IL, Kolla RV, Hoffmann A, Hedrick SM. Cutting edge: innate immunity conferred by B cells is regulated by caspase-8. J Immunol 2005;175:3469-3473. [PubMed: 16148088]

132. Lemmers B, et al. Essential role for caspase-8 in Toll-like receptors and NFkB signaling. J Biol Chem 2007;282:7416-7423. [PubMed: 17213198]

133. Akira S, Takeda K. Toll-like receptor signalling. Nat Rev Immunol 2004;4:499-511. [PubMed: 15229469]

134. Woo M, et al. Caspase-3 regulates cell cycle in B cells: a consequence of substrate specificity. Nat Immunol 2003;4:1016-1022. [PubMed: 12970760]

135. Park JA, Kim KW, Kim SI, Lee SK. Caspase 3 specifically cleaves p21WAF1/CIP1 in the earlier stage of apoptosis in SK-HEP-1 human hepatoma cells. Eur J Biochem 1998;257:242-248. [PubMed: 9799125]

136. Gervais JL, Seth P, Zhang H. Cleavage of CDK inhibitor p21(Cip1/Waf1) by caspases is an early event during DNA damage-induced apoptosis. J Biol Chem 1998;273:19207-19212. [PubMed: 9668108]

137. Moldovan GL, Pfander B, Jentsch S. PCNA, the maestro of the replication fork. Cell 2007;129:665679. [PubMed: 17512402]

138. Xiong Y, Zhang H, Beach D. D type cyclins associate with multiple protein kinases and the DNA replication and repair factor PCNA. Cell 1992;71:505-514. [PubMed: 1358458]

139. LaBaer J, et al. New functional activities for the p21 family of CDK inhibitors. Genes Dev 1997;11:847-862. [PubMed: 9106657]

140. Weiss RH, Joo A, Randour C. p21(Waf1/Cip1) is an assembly factor required for platelet-derived growth factor-induced vascular smooth muscle cell proliferation. J Biol Chem 2000;275:1028510290. [PubMed: 10744715]

141. Cheng M, et al. The p21(Cip1) and p27(Kip1) CDK 'inhibitors' are essential activators of cyclin Ddependent kinases in murine fibroblasts. EMBO J 1999;18:1583.

142. Olson NE, Graves JD, Shu GL, Ryan EJ, Clark EA. Caspase activity is required for stimulated B lymphocytes to enter the cell cycle. J Immunol 2003;170:6065-6072. [PubMed: 12794135]

143. Werz O, et al. Caspase-mediated degradation of human 5-lipoxygenase in B lymphocytic cells. Proc Natl Acad Sci USA 2005;102:13164-13169. [PubMed: 16135563]

144. Zheng TS, et al. Deficiency in caspase- 9 or caspase-3 induces compensatory caspase activation. Nat Med 2000;6:1241-1247. [PubMed: 11062535]

145. D'Sa C, et al. Caspase regulation of genotoxin-induced neural precursor cell death. J Neurosci Res 2003;74:435-445. [PubMed: 14598320]

146. Watanabe C, Shu GL, Zheng TS, Flavell RA, Clark EA. Caspase-6 regulates B cell activation and differentiation into plasma cells. Under revision. 2008

147. Chen-Kiang S. Cell-cycle control of plasma cell differentiation and tumorigenesis. Immunol Rev 2003;164:39-47. [PubMed: 12846806] 
148. Underhill GH, George D, Bremer EG, Kansas GS. Gene expression profiling reveals a highly specialized genetic program of plasma cells. Blood 2003;101:4013-4021. [PubMed: 12543863]

149. Galande S, Dickinson LA, Mian IS, Sikorska M, Kohwi-Shigematsu T. SATB1 cleavage by caspase 6 disrupts PDZ domain-mediated dimerization, causing detachment from chromatin early in T-cell apoptosis. Mol Cell Biol 2001;21:5591-5604. [PubMed: 11463840]

150. Eymin B, et al. Caspase-induced proteolysis of the cyclin-dependent kinase inhibitor p27Kip1 mediates its anti-apoptotic activity. Oncogene 1999;18:4847.

151. Cohen LY, et al. Notch1 antiapoptotic activity is abrogated by caspase cleavage in dying $\mathrm{T}$ lymphocytes. Cell Death Differ 2005;12:243-254. [PubMed: 15650752]

152. Nyormoi O, Wang Z, Doan D, Ruiz M, McConkey D, Bar-Eli M. Transcription factor AP-2alpha is preferentially cleaved by caspase 6 and degraded by proteasome during tumor necrosis factor alpha-induced apoptosis in breast cancer cells. Mol Cell Biol 2001;21:4856-4867. [PubMed: 11438643]

153. Takahashi A, et al. Cleavage of lamin A by Mch2 alpha but not CPP32: multiple interleukin 1 betaconverting enzyme-related proteases with distinct substrate recognition properties are active in apoptosis. Proc Natl Acad Sci USA 1996;93:8395-8400. [PubMed: 8710882]

154. Rokudai S, Fujita N, Hashimoto Y, Tsuruo T. Cleavage and inactivation of antiapoptotic Akt/PKB by caspases during apoptosis. J Cell Physiol 2000;182:290-296. [PubMed: 10623893]

155. Chau BN, Wangm JY. Coordinated regulation of life and death by RB. Nat Rev Cancer 2003;3:130138. [PubMed: 12563312]

156. Skapek SX, Pan YR, Lee EY. Regulation of cell lineage specification by the retinoblastoma tumor suppressor. Oncogene 2006;25:5268-5276. [PubMed: 16936747]

157. De Vos J, et al. Comparison of gene expression profiling between malignant and normal plasma cells with oligonucleotide arrays. Oncogene 2002;21:6848-6857. [PubMed: 12360412]

158. Santambrogio L, Potolicchio I, Fessler SP, Wong SH, Raposo G, Strominger JL. Involvement of caspase-cleaved and intact adaptor protein 1 complex in endosomal remodeling in maturing dendritic cells. Nat Immunol 2005;6:1020-1028. [PubMed: 16170319]

159. Hardy RR. B-1 B cell development. J Immunol 2006;177:2749-2754. [PubMed: 16920907]

160. Fleming HE, Paige CJ. Cooperation between IL-7 and the pre-B cell receptor: a key to B cell selection. Semin Immunol 2002;14:423-430. [PubMed: 12457615]

161. O'Neill RM, Hassan J, Reen DJ. IL-7-regulated homeostatic maintenance of recent thymic emigrants in association with caspase-mediated cell proliferation and apoptotic cell death. J Immunol 2003;170:4524-4531. [PubMed: 12707329]

162. Fischer SF, Bouillet P, O'Donnell K, Light A, Tarlinton DM, Strasser A. Proapoptotic BH3-only protein Bim is essential for developmentally programmed death of germinal center-derived memory B cells and antibody-forming cells. Blood 2007;110:3978-3984. [PubMed: 17720882]

163. Liu YJ, Oldfield S, MacLennan IC. Memory B cells in T cell-dependent antibody responses colonize the splenic marginal zones. Eur J Immunol 1988;182:355-362. [PubMed: 3258564]

164. Clark EA, Ledbetter JA. How does B cell depletion therapy work, and how can it be improved? Ann Rheum Dis 2005;64(Suppl 4):iv77-iv80. [PubMed: 16239394]

165. Gray D, Gray M, Barr T. Innate responses of B cells. Eur J Immunol 2007;37:3304-3310. [PubMed: 18000957]

166. Tam CS, Keating MJ. Chemoimmunotherapy of chronic lymphocytic leukemia. Best Pract Res Clin Haematol 2007;202:479-498. [PubMed: 17707835]

167. Pathan NI, Chu P, Hariharan K, Cheney C, Molina A, Byrd J. Mediation of apoptosis by and antitumor activity of lumiliximab in chronic lymphocytic leukemia cells and CD23+ lymphoma cell lines. Blood 2008;111:1594-1602. [PubMed: 18032710] 

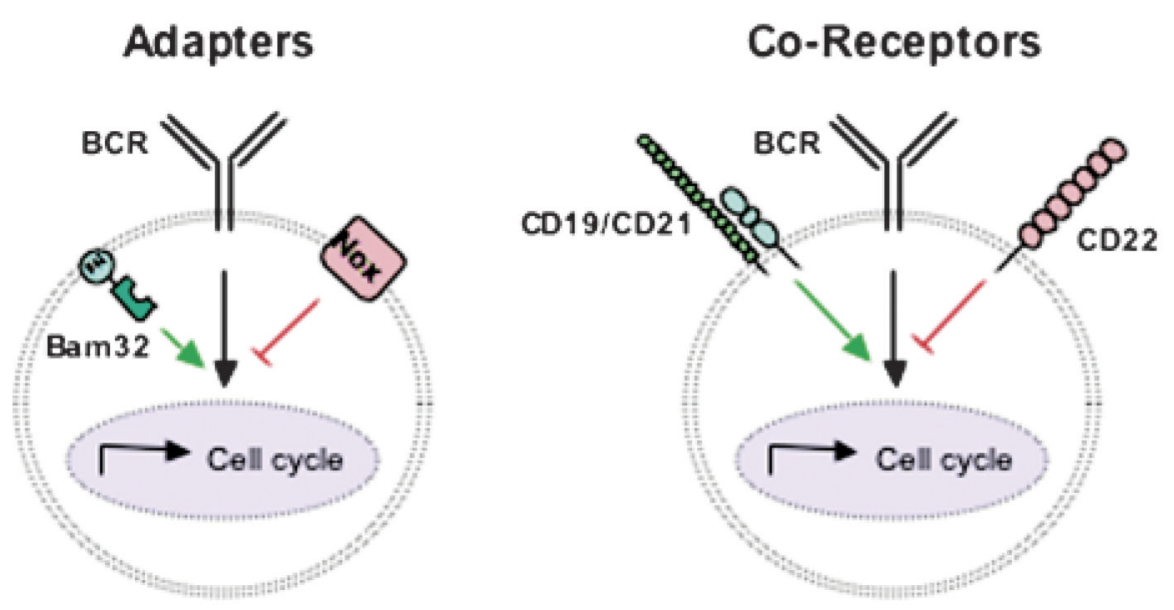

\section{Downstream \\ Regulators}

Fig. 1. Signaling elements that modulate B-cell entry into the cell cycle

B lymphocytes receive mitogenic signals through receptors such as the BCR or TLRs.

Proximally, adapter proteins like Bam32 and components of the NADPH oxidase complex

(Nox) can function to positively or negatively modulate BCR signaling. BCR signals are also modulated by CD22 or CD19 coreceptors associating with the BCR. Finally, downstream regulators, including caspases and Bcl-2 family members such as Bim, influence the rate of Bcell entry into the cell cycle. 


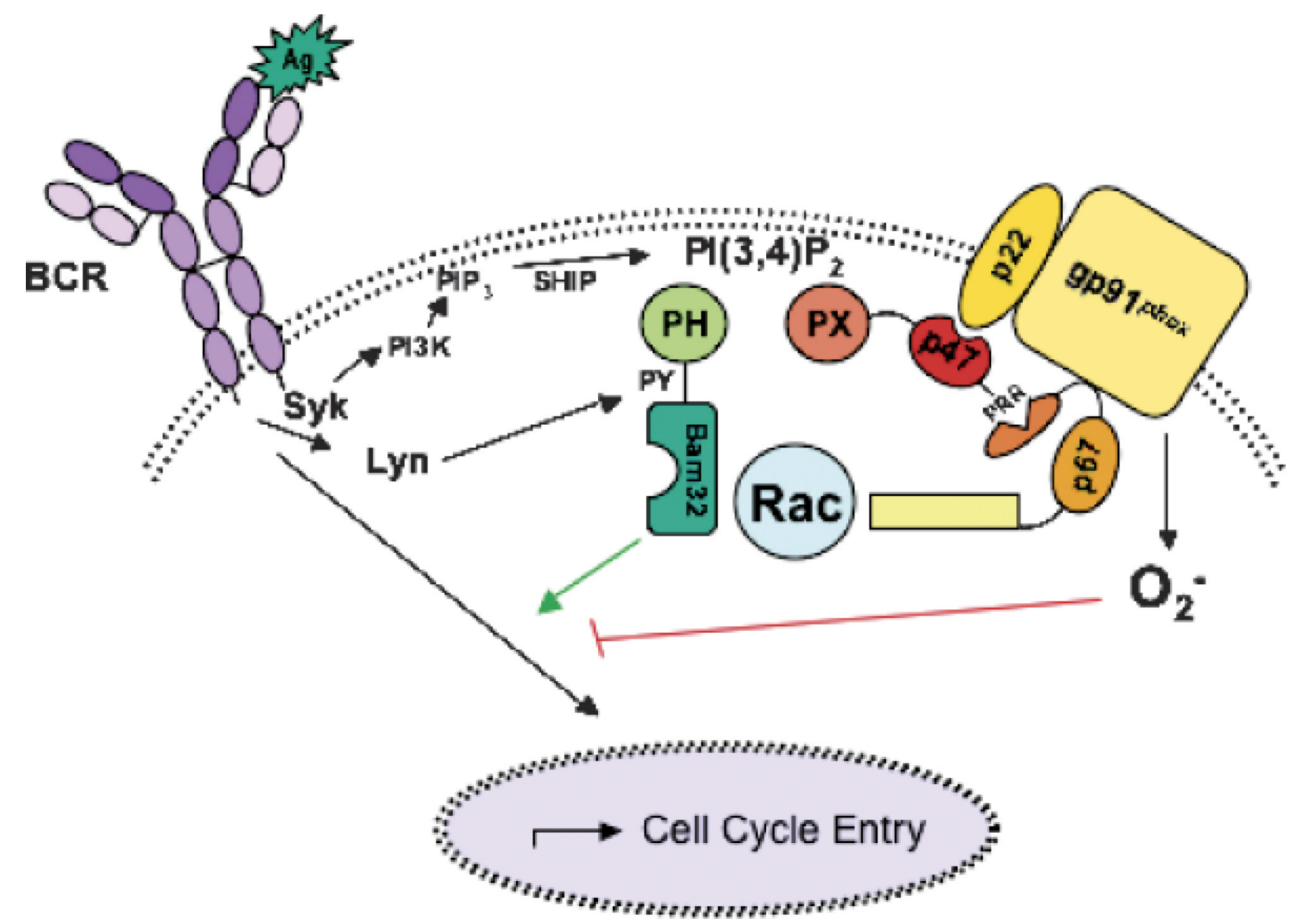

Fig. 2. Competition between Bam32 and the NADPH oxidase complex in B cells Ag triggering of the BCR initiates activation of PTKs Syk and Lyn. Syk activates the PI3K pathway, responsible for catalyzing the formation of $\mathrm{PIP}_{3}$. Bam32 and $4^{\text {phox }}$ are recruited to the cell surface when the SHOP phosphatase converts PIP3 to PI(3,4)P2. Lyn phosphorylates Y139 on Bam32, a key step in Bam32's ability to modulate downstream pathways. Bam32 and the NADPH oxidase compete not only for access to a limited pool of inositol lipids but also for a limited pool of the small GTPase Rac. Retardation of Bam32 KOI B-cell entry into the cell cycle may be due in part to enhanced BCR-induced superoxide generation. 
A
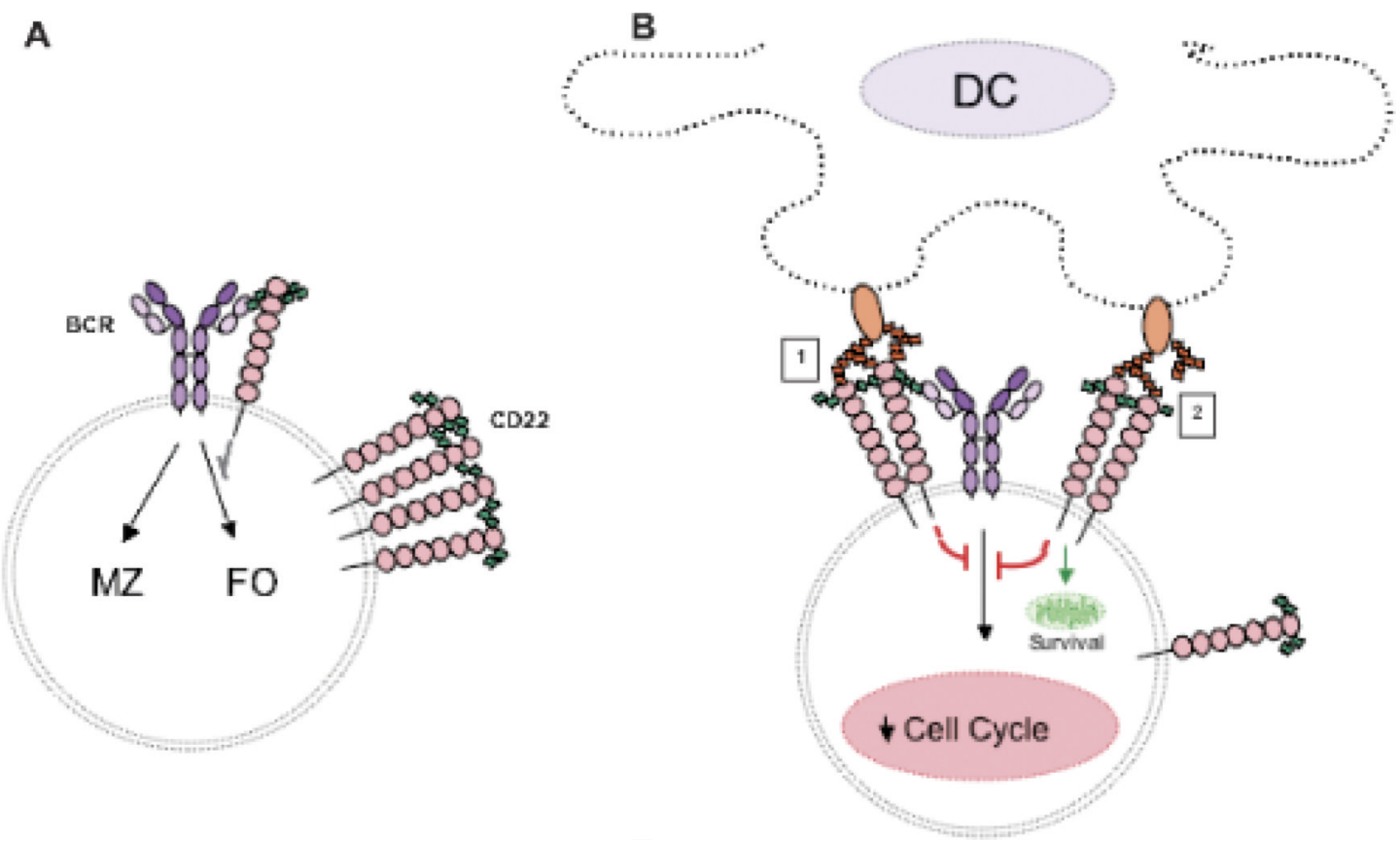

Fig. 3. Cis and trans CD22-CD22L interactions send qualitatively different signals to B cells (A) Cis CD22-CD22L interactions attenuate BCR signaling so the thresholds required for Aginduced B-cell activation and for MZ of FO B-cell development are shifted. (B) Trans interactions between B-cell CD22 and DC-CD22L on the DC disrupts complex formation and allows CD22 signaling to promote survival and block B-cell entry into the cell cycle. The nature of DC-CD22L shown in orange is not known. 


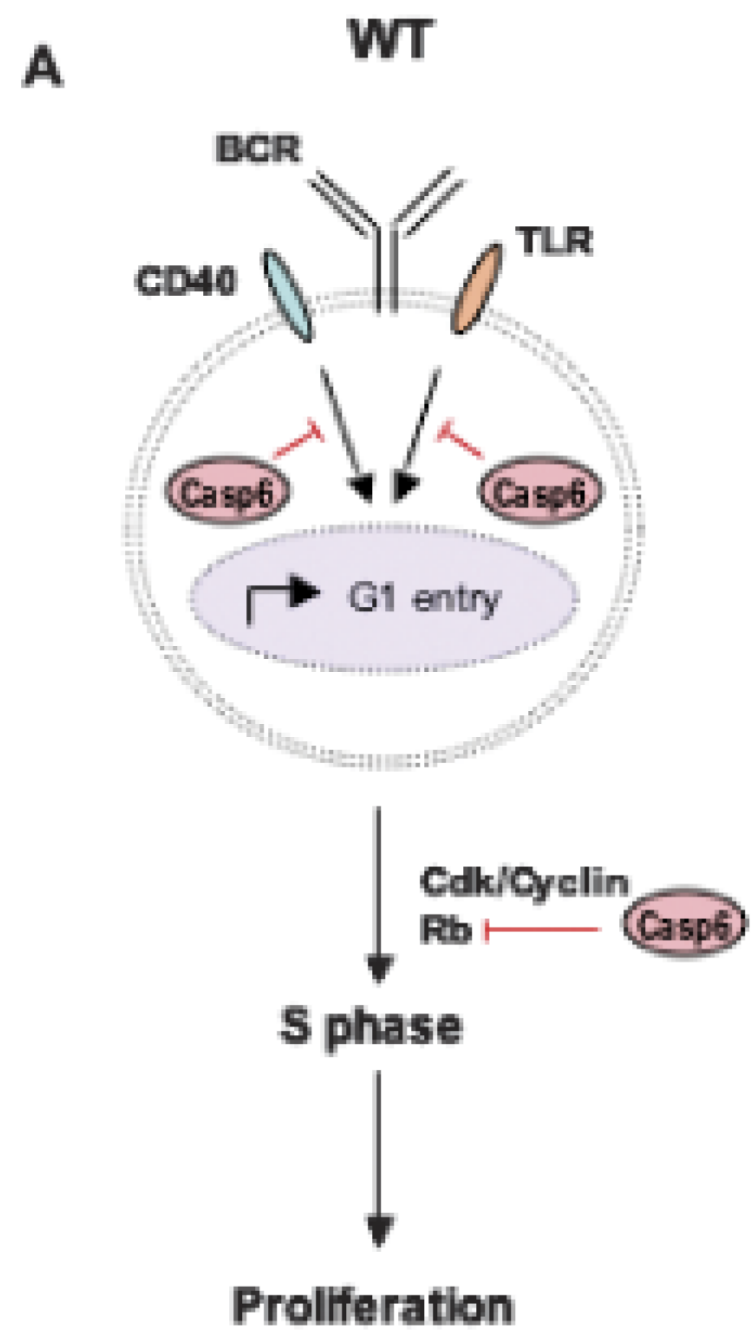

B Casp6 KO

Fig. 4. Regulation of $B$-cell entry into $G_{1}$ by Caspase-6

Casp6 cleaves and inactivates substrates, which inhibit B cells from progressing from G0 into G1 after mitogenic stimulation. Casp6 may also target as a substrate, $\mathrm{Rb}$, which suppresses $\mathrm{S}$ phase entry. In Caps6 KO B cells, elevated levels of Rb protein inhibit proliferation, even though more Casp6 KO B cells enter G1. Instead, differentiation into plasma cells and Ig production are increased. 
Table 1

Rac activation and superoxide production are regulated by Bam32 expression in DT40 cells

\begin{tabular}{llll}
\hline & \multicolumn{1}{c}{ BCR-induced } & \\
Bam32 Levels & & Rac activity & Superoxide \\
None & + & $++{ }^{*}$ \\
Wildtype & ++ & $+{ }^{*}$ \\
Overexpressed & +++ & - \\
\hline
\end{tabular}

Bam32, B-lymphocyte adapter of $32 \mathrm{kDa}$; BCR, B-cell receptor.

* Results obtained in both DT40 B cells and primary mouse B cells (based on (53) and Richards et al., unpublished data, 2008). 